\title{
Global Interventions for Seismic Upgrading of Substandard RC Buildings
}

\author{
G.E Thermou ${ }^{1}$, S.J. Pantazopoulou ${ }^{2}$, M. ASCE, A.S. Elnashai ${ }^{3}$, F. ASCE
}

\begin{abstract}
A methodology for design and proportioning of interventions for seismic upgrading of substandard reinforced concrete (RC) buildings is developed in this paper. The retrofit approach is presented in the form of a simple design tool that aims at both demand reduction and enhancement of force and deformation supply through controlled modification of stiffness along the height of the building. This objective is achieved by engineering the translational mode-shape of the structure so as to optimize distribution of interstorey drift. Results from the proposed approach are summarized in a spectrum format, where demand expressed in terms of interstorey drift is related to stiffness. Design charts, which relate the characteristics of commonly-used global intervention procedures to influence drift demands are developed to facilitate the retrofit design. Intervention procedures considered in this paper are reinforced-concrete jacketing, addition of reinforced concrete walls, and addition of masonry infills. The proposed methodology is also amenable to adaptation to other strengthening methods such as addition of cross-bracing and others.
\end{abstract}

CE Database subject headings: Buildings; Rehabilitation; Reinforced concrete; Seismic design; Columns; Walls

\footnotetext{
${ }^{1}$ Lecturer, Civil Engng. Dept., Laboratory of RC and Masonry Structures, Aristotle Univ. of Thessaloniki, Thessaloniki 54124, Greece, e-mail: gthermou@ @ivil.auth.gr, tel/fax: +30-2310-995466 (Corresponding author) ${ }^{2}$ Professor, Civil Engng. Dept., Laboratory of Reinforced Concrete, Demokritus Univ. of Thrace, Vas. Sofias 12, Xanthi 67100, Greece, email: pantaz@civil.duth.gr

${ }^{3}$ William J. \& Elaine F. Hall Endowed Professor, Civil and Environmental Engineering Dept., Univ. of Illinois at Urbana-Champaign, 2129e Newmark Lab., 205 N. Mathews Ave, Urbana, IL 61801, USA, e-mail: aelnash@illinois.edu
} 


\section{INTRODUCTION}

Earthquakes have repeatedly illustrated the deficiencies of older reinforced concrete construction built prior to the proliferation of contemporary earthquake design principles. A broad category under this description represents structures with vertical irregularities in distribution of stiffness or mass, such as multistory residential buildings with open first storey, which are known to be susceptible to soft-storey formations leading to severe damage or collapse (Fig. 1).

Under earthquake loading, failure will occur where deformation demand exceeds the deformation capacity of the gravity load-carrying members of the structure (i.e.. in columns). Therefore, in order to protect vulnerable structures, an effective approach is to enhance the capacity and simultaneously reduce the demand. In the context of the present paper, deformation demand is quantified by interstorey drift $(I D)$ throughout the structure. Therefore, ID demand depends entirely on the global amount and distribution of structural stiffness at least up to the point of yielding in conventional pushover analysis. Deformation supply refers to the individual elements of the structure; it is controlled by availability of confinement, shear reinforcement, lap and anchorage conditions, ratio of compression to tension reinforcement and amount of axial compression. Many (but not all) of those deficiencies in deformation capacity can be alleviated through local interventions.

In the context of a rehabilitation strategy framework, the proposed methodology aims at systematic reduction of deformation demand, and in particular, elimination of any tendency for localization of demand in parts of the structural system. The degree of stiffness irregularity in the structure and the resulting local increase in the magnitude of demand (i.e., the magnitude of imposed $I D$ ) during an earthquake may be diagnosed by the morphology of the fundamental translational mode of vibration. For example, a uniform distribution of $I D$ would correspond to a linear first mode shape; in this case, the lateral translation increment in 
the mode shape coordinate from floor to floor equals to $1 / n$, where $n$ is the number of floors (Fig. 2(a)). A shear-type first mode is marked by higher increments in the lower floors gradually decreasing towards the upper floors (Fig. 2(b)). The reverse pattern occurs in a flexural-type translational mode (Fig. 2(c)). In a soft storey formation, the mode shape is practically constant above the soft storey (that is, negligible $I D$ occurs in all floors but within the soft storey, Fig. 2(d)).

In a reverse process of redesign, where the desirable pattern of $I D$ distribution prescribes the proper morphology of the fundamental mode shape, it is relatively straightforward to evaluate the pattern of stiffness distribution throughout the structure, required to produce a desirable translational mode. The necessary stiffness that is estimated from this process can be added through pertinent interventions in each floor as required. Dimensioning and detailing of these interventions refers to basic mechanics of reinforced concrete. Examples of stiffness-modifying interventions are, (a) reinforced concrete jacketing of columns, (b) addition of reinforced concrete walls, (c) addition of masonry infills or steel cross-braces, (d) addition of metal or FRP longitudinal reinforcement in columns, properly anchored in the ends, and combined with pertinent transverse jacketing for confinement. Note that implementation of some of these interventions (e.g., case (b)), may require a more extensive solution that would also involve upgrading of the foundation, whereas other methods (such as for example, case (d)) are only supported so far by very limited experimental evidence.

In the remainder of this paper, design calculations, including stiffness values, refer to the onset of yielding (secant stiffness values). Thus, vertical members are dimensioned to match the required stiffness and a selected target value of $I D_{y, \text { target }}$ at yielding. The process is facilitated by development of the Interstorey Drift Spectra (IDS), which relate the characteristics of familiar global intervention procedures to the magnitude of interstorey drift 
demands $(I D D)$ during earthquakes. These results may also serve as rapid inspection tools that facilitate immediate assessment of the effect on IDD, produced by changes in the technological details of the intervention methods.

CONTROL OF LATERAL RESPONSE IN SEISMIC UPGRADING OF BUILDINGS

\section{Controlled distribution of damage along the height of the building}

$I D D$ is considered in earthquake engineering as the most representative index of damage assessment, and for this reason it is related directly to definition of performance objectives both in design and rehabilitation. For a given level of building lateral translation, limiting the magnitude and distribution of $I D D$ in the structure may be managed by controlling the relative displacement pattern implicit in the modes of vibration that mostly affect dynamic response. In the proposed rehabilitation framework, the lateral response of the building is explicitly modified through retrofitting, by targeting towards a desirable pattern for the fundamental mode of translational vibration.

\section{Selection of the appropriate target response shape}

A point of reference in selecting the target response shape are, the fundamental mode and period of the existing building. These may be evaluated rapidly through standard Rayleightype or Stodola-type iteration (Clough and Penzien 1993), using secant-to-yield stiffness values for the individual members. The estimated fundamental translational response shape and period may guide definition of retrofit objectives: an excessively large fundamental period value identifies the need of lateral strengthening of the building (owing to the implicit relationship between stiffness and strength) by means of controlled stiffness addition along the building height. Proportioning the stiffness of the individual floors is determined so as to 
even out large discrepancies in relative drift between successive floors detected in the fundamental response shape pattern.

For lightly reinforced frames or flat-slab structures an acceptable retrofit scenario may be developed by targeting at a response shape that ranges between a controlled shear- and the triangular profile (Fig. 2). Complete alteration of the fundamental response shape from a shear to a flexural - type profile would require addition of excessive amounts of lateral stiffness to the structure. For usual pilotis buildings (Fig. 1, 2(d)) this would most likely exceed the strength and stiffness needed in order to achieve a commonly acceptable frame response.

\section{Achievement of target deformation shape by stiffness adjustment}

Consider a planar frame structure with lumped floor masses vibrating in a single lateral displacement shape, $\Phi$. If the shape is normalized with respect to the displacement at the top of the building, $\Delta_{t o p}$, it follows that the $i$-th floor displacement is, $\Delta_{i}=\Phi_{i} \Delta_{\text {top }}$ and the corresponding interstorey drift is, $\theta_{i}=\left(\Phi_{i^{-}} \Phi_{i-1}\right) \cdot \Delta_{t o p} / h_{i}=\Delta \Phi_{i} \cdot \Delta_{t o p} / h_{i}$. The generalized properties of the equivalent single degree of freedom system (ESDOF) and its associated equation of motion are given by (Clough and Penzien 1993):

$$
M^{*}=\sum_{i=1}^{n} m_{i} \Phi_{i}{ }^{2}, K^{*}=\sum_{i=1}^{n} K_{i} \Delta \Phi_{i}{ }^{2}, \omega^{2}=\frac{K^{*}}{M^{*}}, \ddot{Y}+2 \xi \omega \dot{Y}+\omega^{2} Y=-\left(L^{*} / M^{*}\right) \ddot{u_{g}}
$$

where $L^{*}=\Sigma m_{i} \Phi_{i}$, whereas, $m_{i}$ and $K_{i}$ are the translational mass and stiffness terms of the $i$-th floor ( $K_{i}$ corresponds to onset of yielding). Note that contribution of a floor's translational stiffness to the generalized structural stiffness $K^{*}$ is controlled through the term $\Delta \Phi_{i}$ in (Eq. 1 ). Corollary to this is that a floor does not contribute to the generalized stiffness if the corresponding floor value of $\Delta \Phi_{i}$ is zero - this is the extreme case of structures with a soft first storey (Fig. 2(d)) where $\Delta \Phi_{i} \approx 0$ for the upper floors (i.e., although these floors have 
larger stiffness than the soft storey, they do not contribute to the generalized translational stiffness of the structure).

The reverse problem of establishing the required translational stiffness values in order to achieve a target shape $\Phi_{i}$, is solved from the eigenvalue problem of a planar multistory structure with lumped properties and translational degrees of freedom (d.o.f.):

$$
\omega^{2} \cdot \underline{F} \cdot \underline{m}=\underline{I} \Rightarrow \omega^{2} \cdot \underline{F} \cdot \underline{m} \cdot \underline{\Phi}=\underline{\Phi}
$$

where $\underline{m}$ and $\underline{F}$ are the mass and flexibility matrices of the structure. By definition $F_{i j}$ is the displacement at d.o.f $-j$, produced by a unit force acting along the d.o.f - $i$. For frame structures with one translational degree of freedom per individual floor (i.e., when floor rotations are either negligible or condensed out of the equation of motion in the absence of associated mass), the above takes the following form:

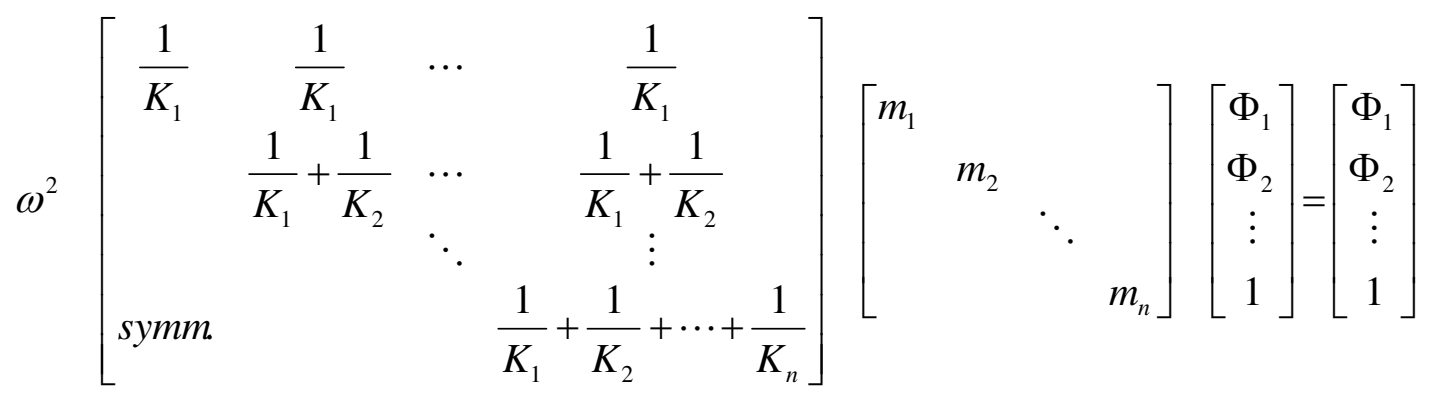

Terms $K_{l}, K_{2}$, etc. are the work-equivalent translational stiffnesses of the individual floors (degrees of freedom are numbered from the first storey upwards). For a given target shape (i.e., for known $\Phi_{i}$ values), the first equation above is solved for the required value of $K_{1}$, next, the second equation is solved for $K_{2}$, and so on. Clearly the system with stiffness distribution satisfying Eq. (2) will have a fundamental response shape equal to the enforced target shape, $\Phi$. Note that since $\omega$ is a multiplier, the above equations prescribe the required ratio between various floor stiffness values $\left(\kappa_{2}=K_{2}: K_{1}, \kappa_{3}=K_{3}: K_{1}, \ldots, \kappa_{n}=K_{n}: K_{1}\right)$ in order for the building to achieve the target shape. For equal mass, Fig. 3 depicts the required floor 
stiffness ratios $\left(\kappa_{i}=K_{i}: K_{l}\right.$, where $i=2, \ldots$, n-number of floors $)$ for different lateral deflection shape patterns for 2- up to 8-storey frame buildings (expressions for $\kappa_{i}$ are listed in Table 1.)

Furthermore, if a target value is selected for the period of the structure (i.e., specified $\omega)$ the exact $K_{i}$ values may also be estimated from Eq. 2(b). (Current codes specify upper limits for the expected value of the fundamental period of an adequately designed building, in terms of total height or number of floors; exceeding these limits by a substantial margin indicates that the structure is overly flexible and stiffening may be called for). In Fig. 4, assuming the same floor mass, $m$, and the same storey height, $h_{i}$, throughout the building, the prescribed value of $K_{l}$ is given for buildings with different numbers of storeys, using as a rule of thumb for the fundamental period the empirical expression for frame structures $T=0.075\left(n \cdot h_{i}\right)^{3 / 4}$ (EC8-I 2004), where $n$ is the number of storeys; (for derivation of Fig. 4 the triangular response shape was used with a storey height, $h_{i}=3 \mathrm{~m}$ and unit storey mass, $m=1$ ton. For other mass values, the ordinate axis must be multiplied by this value).

\section{Storey stiffness contribution to generalized stiffness}

The translational stiffness of the $\mathrm{i}$-th storey, termed as $K_{i}(i=1,2, \ldots n)$ in Eq. $(2 \mathrm{~b})$, and its contribution to the structure's generalized stiffness $K^{*}$ in Eq. (1), is given by the sum of the work equivalent stiffness terms of its individual members $(j=1,2, \ldots \ell)$. To calculate the work equivalent stiffness contribution of the $j$-th element (beam, column, or wall) of the $i$-th floor, consider the chord rotations $\theta_{j}{ }^{1}, \theta_{j}^{2}$ developing in the ends of that member when the structure deflects laterally following the applied deflection shape, $\Phi$ (Fig. 5(a)); end moments of each member are obtained from the deformational member stiffness matrix:

$$
\left\{\begin{array}{l}
M_{j}^{l} \\
M_{j}^{2}
\end{array}\right\}=\frac{E_{c} I_{y, j}}{\left(1+\beta_{j}\right) L_{j}}\left(\begin{array}{cc}
4+\beta_{j} & 2-\beta_{j} \\
2-\beta_{j} & 4+\beta_{j}
\end{array}\right) \cdot\left\{\begin{array}{l}
\theta_{j}^{1} \\
\theta_{j}^{2}
\end{array}\right\}
$$


Coefficient $\beta$ accounts for the contribution of shear deformations in the response; for frame members, $\beta_{j}$ may be taken equal to zero without great loss of accuracy (i.e. neglecting shear deformations), whereas in the case of walls, terms $(4+\beta) /(1+\beta)$ and $(2-\beta) /(1+\beta)$ account for the work done by shear deformations in the wall in addition to that by flexural curvature. Term $\beta=24 a_{s h}\left(1+v_{P}\right)\left(r_{w} / h_{i}\right)^{2}$, where $r_{w}$ is the radius of gyration of the wall cross section in the direction of main action, $a_{s h}$ is the ratio of the walls's shear area to its total cross section $(\approx 0.8)$, and $v_{P}$ is the material's Poisson's ratio $\left(\alpha_{s h}\left(1+v_{p}\right) \approx 1\right)$. It is also assumed that the deformed structure is forced to undergo a virtual displacement pattern which, for convenience, is taken identical to the deflected shape, i.e., $\delta \Phi=\Phi$; based on this postulate, virtual rotations $\delta \theta_{j}{ }^{l}$, and $\delta \theta_{j}^{2}$ at individual member ends are respectively equal to $\theta_{j}{ }^{1}, \theta_{j}^{2}$. The resulting virtual work expression for a single storey is:

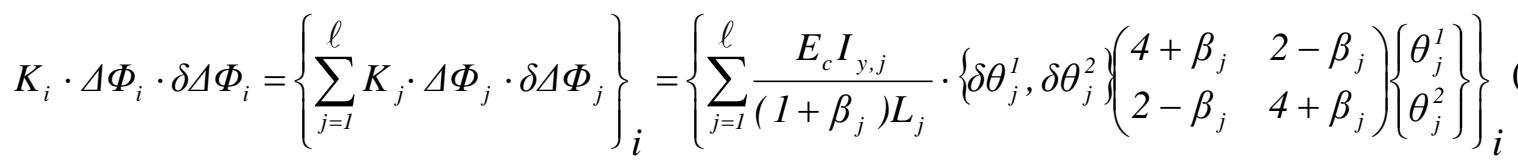

The notation used $\{\ldots\}_{i}$ denotes that the operation inside the \{\} concerns the $\ell$ members that belong in the $i_{\text {th }}$ floor. Member end rotations are related to the interstorey drift magnitude of the storey under consideration, $\theta_{i}=\Delta \Phi_{i} / h_{i}$, and to the slope of the tangent to the deflected shape at the bottom and top of that storey. Thus, $\theta_{j}^{1}=\left.\theta_{i^{-}}(d \Phi / d z)\right|_{z=z i}$, and $\theta_{j}^{2}=\theta_{i^{-}}$ $\left.(d \Phi / d z)\right|_{z=z i+h i}$. Note that the wall generally deflects laterally without reversal of moments within a single floor, so in general, $\theta_{w}{ }^{1} \neq \theta_{w}{ }^{2}$. (For flexure-type response, terms $d \Phi / d z$, correspond to the floor rotations at the levels where the translational d.o.f. are located; these increase from the lower to the upper floors, thereby moderating the deformations in the vertical elements (Fig. 5(b)). In shear-type response floor rotations are negligible, thus, end rotations of each column are well approximated by the value of the interstorey drift, (Fig. $5(\mathrm{c}))$; for a shape of virtual displacements identical to that of the deflected shape, $(\delta \Phi=\Phi)$ 
virtual rotations at member ends become equal to the corresponding actual rotations (i.e. $\delta \theta_{j}^{1}=\theta_{j}^{1} ; \delta \theta_{j}^{2}=\theta_{j}^{2}$.

Wall systems or wall-equivalent dual systems: Storey stiffness contribution as described by Eq. (4) is written in general form as:

$$
\begin{aligned}
& K_{i} \cdot \Delta \Phi_{i} \cdot \delta \Delta \Phi_{i}=\left\{\sum_{j=1}^{\ell_{w}} K_{j} \cdot \Delta \Phi_{j} \cdot \delta \Delta \Phi_{j}\right\}_{i}=\left\{\sum_{j=1}^{\ell_{w}} \frac{\left\{4 \Theta_{w, j}^{A}+\beta_{j} \Theta_{w, j}^{B}\right\} h_{i}^{2}}{\left(1+\beta_{j}\right)} \frac{E_{c} I_{y, j}^{w}}{h_{i}^{3}}\right\}_{i}=\left\{\sum_{j=1}^{\ell_{w}} \alpha_{w, j} \frac{E_{c} I_{y, j}^{w}}{h_{i}^{3}}\right\}_{i} \\
& \alpha_{w, j}=\frac{\left\{4 \Theta_{w, j}^{A}+\beta_{j} \Theta_{w, j}^{B}\right\} h_{i}^{2}}{\left(1+\beta_{j}\right)} ; \Theta_{w, j}^{A}=\left(\theta_{w, j}^{1}\right)^{2}+\theta_{w, j}^{1} \theta_{w, j}^{2}+\left(\theta_{w, j}^{2}\right)^{2}, \Theta_{w, j}^{B}=\left(\theta_{w, j}^{1}\right)^{2}-2 \theta_{w, j}^{1} \theta_{w, j}^{2}+\left(\theta_{w, j}^{2}\right)^{2}
\end{aligned}
$$

Terms $\Theta_{w, j}{ }^{A}$ and $\Theta_{w, j}{ }^{B}$ are defined in Tables $\mathrm{A}_{1}$ and $\mathrm{A}_{2}$ of the Appendix for the flexural response shape $\left(\Phi_{i}=1-\cos (\pi i /(2 n))\right)$ for various numbers of floors as a function of the square power of the storey height $\left(h_{i}{ }^{2}\right)$. Thus, the wall stiffness at the $i$-th storey may be estimated directly from Eq. (5) using Tables $A_{1}$ and $A_{2}$.

Frame structures: When neglecting shear deformations Eq. (4) takes on the familiar form:

$$
K_{i} \cdot \Delta \Phi_{i} \cdot \delta \Delta \Phi_{i}=\left\{\sum_{j=1}^{\ell} K_{j} \cdot \Delta \Phi_{j} \cdot \delta \Delta \Phi_{j}\right\}_{i}=\left\{\sum_{j=1}^{\ell} \frac{6 E_{c} I_{y, j}}{L_{j}} \cdot\left[\theta_{j}^{1} \cdot \delta \theta_{j}^{1}+\theta_{j}^{2} \cdot \delta \theta_{j}^{2}\right]\right\}_{i}
$$

The moment equilibrium at the beam-column joints depends on the relative stiffness ratio of the $n_{b}$ beams and the $n_{c}$ columns that converge at a typical floor joint: $\lambda=n_{b} E I_{b} \cdot h_{c} /\left(n_{c} E I_{c} \cdot L_{b}\right)$. Thus, under lateral sway by an interstorey drift of $\theta_{i}$, beam ends in the $i$-th floor rotate by the amount $\theta_{b, j}{ }^{1}=\theta_{b, j}{ }^{2}=[1 /(\lambda+1)] \theta_{i}=\lambda_{b} \theta_{i}$ (assumed point of inflection at midspan; at low drift levels the actual moment diagram deviates from this approximation in the beams since moments owing to gravity loads may be comparable to those caused by lateral drift. At higher drift levels seismic moments exceed by a substantial margin the end moments due to gravity, and therefore near the point at yielding the assumption of an inflection point near the midspan becomes more reasonable). Similarly, column ends rotate by the amount, $\theta_{c, j}{ }^{1}=\theta_{c, j}{ }^{2}=[\lambda /(1+\lambda)] \theta_{i}=\lambda_{c} \theta_{i}$ (Fig. 5(a)). A criterion that identifies the expected 
type of lateral deflection pattern (triangular, shear or flexural) is obtained from comparison of the first storey drift $\left(=\lambda_{c} \theta_{l}\right)$ at a given magnitude of top displacement, $\Delta_{t o p}$, to the slope of the tangent to the deflected shape at the first storey, $\left.\Delta_{t o p} \cdot(d \Phi / d z)\right|_{z=h i}$, (assuming the first storey as the most critical). Thus:

$\lambda_{c} \theta_{1}\left\{\begin{array}{l}=\Delta_{\text {top }} \cdot 1 /\left(n h_{i}\right), \text { triangular shape } \\ >\Delta_{\text {top }} \cdot \pi /\left(2 n h_{i}\right) \cdot \cos (\pi /(2 n)), \text {, shear shape } \\ <\Delta_{\text {top }} \cdot \pi /\left(2 n h_{i}\right) \cdot \sin (\pi /(2 n)), \text { flexural shape }\end{array}\right.$

Column deformation (term $\lambda_{c} \theta_{l}$ of Eq. (7)), is different from interstorey drift. Here it is recognized that a part of the interstorey drift is owing to rotations occurring in the beams, referred hereon as "tangential" interstorey drift and established from the derivative of the deflected shape at the top of the column in consideration.

Considering that the typical frame structure responds following a shear or at most, a triangular response profile and that column length, $h_{c}$, is equal to storey height, $h_{i}$, for a representative average value of $\lambda$ for the entire storey, the general expression for the $i$-th floor stiffness as defined by Eq. (6) is further modified to:

$$
K_{i} \cdot \Delta \Phi_{i} \cdot \delta \Delta \Phi_{i}=K_{j}^{b} \cdot \Delta \Phi_{i} \cdot \delta \Delta \Phi_{i}+K_{j}^{c} \cdot \Delta \Phi_{i} \cdot \delta \Delta \Phi_{i}=\lambda_{b}^{2}\left\{\sum_{j=1}^{\ell_{b}} \frac{\alpha_{c, b} E_{c} I_{y, j}^{b}}{L_{b, j} h_{i}^{2}}\right\}_{i}+\lambda_{c}^{2}\left\{\sum_{j=1}^{\ell_{c}} \frac{\alpha_{c, J} E_{c} I_{y, j}^{J}}{h_{i}^{3}}\right\}_{i}(8)
$$

The value of $\lambda$ used in Eqs. (6), (7) and (8) is the average "rotational stiffness ratio" value, calculated for all beam-column joints that belong to the floor in consideration. Coefficient $\alpha_{c, b}=\alpha_{c, J}=12$ refers to full end restraint against rotation $\left(\theta_{j}^{1}=\theta_{j}^{2}=1 / h_{i}\right) ; \alpha_{c, b}=\alpha_{c, J}=3$ corresponds to release of rotational restraint at one end, whereas intermediate values correspond to partial rotational restraints at the member ends. In the triangular response shape the lateral drift is accommodated by deformation at the lower end of the first storey columns only, $\theta_{c, j}{ }^{1}=1 / h_{i}, \theta_{c, j}{ }^{2}=0$, and at all the beam ends, $\theta_{b, j}{ }^{1}=\theta_{b, j}{ }^{2}=1 / h_{i}$ (in adopting a triangular response shape it is implicitly assumed that yielding occurs at the bottom of the first storey 
columns and at the beam ends. Note that in this case $\alpha_{c, b}=12$ in Eq. (8), whereas $\alpha_{c, J}=4$ for $i=1$ in Eq. (8), and $\alpha_{c, J}=0$ for $\left.i>1\right)$.

In the postcracking range of response, if a strong-column/weak-beam design is implemented in the retrofit, the flexural stiffness ratio follows that of the moment strength ratio $(<1: 1.4)$; assuming that the beam span to storey height ratio $L_{b, j} / h_{c, j}$ is near the value of 2 (bending in double curvature), it follows that a value of $\lambda=1 /(2 \times 1.4)=0.36$ is representative for interior connections $\left(n_{b}=n_{c}=2\right)$ (more generally $\lambda<1$ ), leading to $\lambda_{c} \approx 0.24$ and $\lambda_{b} \approx 0.76$.

\section{Definition of demand}

Stiffness calculations described above correspond to the end of the ascending branch (elastic range) of the structure's pushover curve, i.e., the sectional flexural stiffness EI of the members in Eqs. $(3,4,5,6,8)$ is defined by the ratio of yield moment divided by yield curvature. For this reason, demand at the onset of yielding (end of the linear elastic response region) is the point of reference in the present analysis: for a given required initial stiffness (target period) and a target value for the drift at yielding the ductility index of the YPS that goes through the point of yielding in the structure's pushover determines the displacement demand of the performance point, $\Delta_{u}=\mu_{\text {target }} \cdot \Delta_{y}$. This is expressed through Yield Point Spectra (YPS), for the design earthquake (Aschheim and Black, 2000). (The YPS are isoductile total

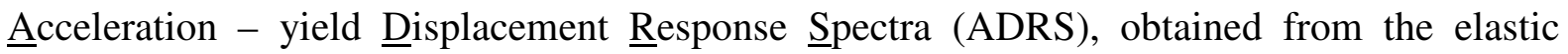
spectrum of the design earthquake after scaling down its $\mathrm{x}$ and $\mathrm{y}$ coordinates through pertinent $q-\mu-T$ relationships. In the simplest case where $q=\mu$ for all $T$ values (equal displacement rule for pairs of linear and nonlinear systems with the same initial stiffness) the total acceleration and relative displacement coordinates of the elastic ADRS spectrum are simply divided by the ductility demand, $\mu_{\text {target }}$, in order to obtain the corresponding YPS. This 
curve goes through the yield point of the ESDOF's pushover curve, and it simultaneously defines the ductility demand when the structure is subjected to the design earthquake.)

\section{GLOBAL INTERVENTIONS IN SEISMIC REHABILITATION OF RC}

\section{STRUCTURES}

Global Intervention $(G I)$ is a retrofit method that results in modification of the global structural stiffness. GI is necessary in systems with a high flexibility to sway, in torsionally unbalanced systems or where strengthening of the existing building is required (e.g. increase of base shear strength in buildings with an open first-storey). In the present study each $G I$ procedure is quantified through the stiffness it contributes to the structure as a whole. Methods considered include reinforced concrete (RC) jacketing, addition of RC walls or infill masonry walls. For simplicity, only structures with vertical irregularities are considered here. Additional criteria aiming to control the torsional component of the response have been developed by Pardalopoulos and Pantazopoulou (2010). Although local measures (such as FRP jacketing) are an inseparable attribute of the implemented rehabilitation schemes, they are not considered part of the basic strategy and do not enter into the proportioning algorithm of the global rehabilitation, as they do not alter the stiffness or flexural strength of the retrofitted members, but only affect their post-yielding deformation capacity through confinement and by suppressing premature modes of failure (e.g. brittle shear or lap-splice failure).

\section{Proportioning of retrofit for target shape upgrading}

In order to practically implement the required storey stiffness $K_{i}$ of the retrofitted structure the stiffness of those members that participate in the global intervention scheme is expressed in terms of the technological details of the retrofit. 
(1) Reinforced concrete walls: Addition of either new RC walls or infill walls (partial or full) in strategically-selected bays of the existing frame is also a common method used for strengthening of existing structures. This is particularly suitable for structures with a poor frame action (flat-slab structures) that suffer from an inherent deficiency of lateral stiffness. If the wall occupies a full bay, then it is often designed to incorporate the beams and the two end-columns of the bay, the latter acting as its boundary elements. This method efficiently controls global lateral drift, thus reducing demand in vertical frame members. A prime consideration in design is distribution of the walls so as to avoid plan eccentricity. Other issues concern provisions to secure safe transfer of inertial forces to the walls through floor diaphragms, struts and collectors, integration and connection of the wall into the existing frame buildings and transfer of loads to the foundation. Added walls are typically designed and detailed following current code requirements for new structures. A typical wall cross section is depicted in Fig. 6(a). The relationship between the normalized compression zone depth $\xi_{w}\left(=c / d_{w}\right)$ and the longitudinal reinforcement ratio of the boundary columns, $\rho_{b e}$, is plotted in Fig. 6(b) for various levels of axial load ratio, $v\left(=N /\left(t_{w} h_{w} f_{c}^{\prime}\right)\right)$ and longitudinal reinforcement ratio of the web, $\rho_{w e b}=0.5 \%$. The secant to yield cross sectional stiffness of an RC wall section, $E_{c} I^{w}{ }_{y}$, is obtained from basic mechanics of RC as a function of $\rho_{b e}, v$, and the walls's cross sectional area, $A_{w}$, (Thermou et al. 2009):

$$
E_{c} I_{y}^{w}=E_{c} A_{w}\left(d_{w, J}^{2} i_{w}\right)
$$

Thus, Eq. (5) may be written as follows:

$$
K_{i} \cdot \Delta \Phi_{i} \cdot \delta \Delta \Phi_{i}=\left\{\sum_{j=1}^{\ell_{w}} K_{j}^{w} \cdot \Delta \Phi_{j} \cdot \delta \Delta \Phi_{j}\right\}_{i}=\left\{\sum_{j=1}^{\ell_{w}} \frac{E_{c} A_{w, j} d_{w, j}^{2}}{\left(1+\beta_{j}\right) h_{i}} i_{w, j}\left\{4 \Theta_{w, j}^{A}+\beta_{j} \Theta_{w, j}^{B}\right\}\right\}_{i}
$$

(2) Reinforced concrete jacketing is the most common rehabilitation method for concrete buildings in Southern Europe. Apart from enhancing the deformation capacity of the retrofitted columns, an advantage of jacketing is that it may achieve a more uniform 
distribution of stiffness and strength throughout the plan of the building as compared with the addition of shear walls, while avoiding the pitfalls of the latter approach which invariably requires extensive redesign of the building's foundation in accord with capacity design considerations. Another advantage is that column jacketing continues through the floor diaphragms, thereby encasing the regions of beam-column joints, eliminating the risk of a joint shear failure in the retrofitted structure. A practical difficulty is caused by beams at the beam-column connections, which may require bundling of added longitudinal bars in the corners of the column jacket.

A typical jacketed cross section is idealized in Fig. 7(a) having initial dimensions $b_{c}$ and $h_{c}$, increased to $b_{J}, h_{J}$ after jacketing. The compression zone depth $c$, is normalized as $\xi_{J}=c / d_{J}$; its relationship to the total equivalent reinforcement ratio, $\rho_{e}$, and axial load ratio, $v$ $\left(=N /\left(b_{J} h_{J} f_{c}^{\prime}\right)\right.$, is plotted in Fig. $7(\mathrm{~b})$. The secant to yield cross sectional stiffness of a RC jacketed column, $E_{c} I_{y}^{J}$, may be expressed in terms of $\rho_{e}, v$, and the retrofitted member's cross sectional area, $A_{J}$, using basic concrete mechanics (Thermou et al. 2009):

$$
E_{c} I_{y}^{J}=E_{c} A_{J}\left(d_{J}^{2} i_{J}\right)
$$

Similarly, the secant-to-yield cross-sectional stiffness of a $\mathrm{RC}$ beam, $E_{c} l^{b}$, and associated translational floor stiffness of the frame structure (from Eq. 8) is:

$$
\begin{aligned}
& E_{c} I_{y}^{b}=E_{c} A_{b}\left(d_{b}^{2} i_{b}\right) \\
& K_{i} \cdot \Delta \Phi_{i} \cdot \delta \Delta \Phi_{i}=\lambda_{b}^{2}\left\{\sum_{j=1}^{\ell_{b}} \frac{\alpha_{c, b} E_{c} A_{b} d_{b, j}^{2}}{L_{b, j} h_{i}^{2}}\right\}_{i}+\lambda_{c}^{2}\left\{\sum_{j=1}^{\ell_{c}} \frac{\alpha_{c, J} E_{c} A_{b} d_{J, j}^{2}}{h_{i}^{3}}\right\}_{i}
\end{aligned}
$$

(3) Infill masonry walls: Adding infills as a means of retrofitting moment resisting frames (MRF) is a popular method in Southern Europe and it is encouraged by EC8-III (2005); in North America this retrofit method is considered controversial, as it is thought to be increasing the mass of the system without any effect on strength at large ductilities - a 
counterargument is that by adding stiffness in the range of elastic frame response, displacement demands are moderated, provided the wall is connected through its thickness. Caution should be exercised should this option be pursued; the translational stiffness of an infill masonry wall deforming in its plane is estimated with reference to a diagonal strut used to idealize the infills' function as a stiffening link (EC8-I 2004, EC8-III 2005). The stiffness value is a secant measure, obtained from the ratio of the estimated wall lateral force to the corresponding storey distortion. The applied lateral force is equal to the horizontal component of the diagonal strut that forms along the diagonal of the infill panel, $F$ : $K=F / \sin a=F \cdot\left(l_{m w}{ }^{2}+h_{i}{ }^{2}\right)^{1 / 2} / l_{m w}$; it is further assumed that the strength of the strut, $F_{\max }$ is obtained from the product of the compressive strength of the masonry, $f_{w k}$, by the effective area of the strut taken equal to $10 \%$ of the wall area $A_{m w}$. Storey distortion is given by the interstorey lateral displacement, $\theta_{i} h_{i}$. Storey drift $\theta_{i}$ is expressed in terms of the wall's yield distortion, $\theta_{y}{ }^{m w}$, through the level of ductility attained by the infill wall at the point of yielding of the surrounding RC frame, which is denoted here by parameter $\mu_{y}^{m w}$. Therefore,

$$
K_{i} \cdot \Delta \Phi_{i} \cdot \delta \Delta \Phi_{i}=\left\{\sum_{j=l}^{\ell_{m w}} K_{j}^{m w} \cdot \Delta \Phi_{j} \cdot \delta \Delta \Phi_{j}\right\}_{i}=\left\{\frac{0.1 \cdot f_{w k}}{\mu_{y}^{m w} \theta_{y}^{m w} h_{i}} \sum_{j=l}^{\ell_{m w}}\left(1+\frac{h_{i}^{2}}{l_{m w, j}^{2}}\right)^{0.5} A_{m w, j}\right\}_{i}
$$

Secant stiffness of wall infills decays with imposed drift demand. Note that infills "yield" at drift levels in the range of $0.15 \%-0.2 \%$; thus, when the surrounding frame elements are at yielding, i.e. at an interstorey drift in the range of $0.5 \%$, the wall is already at a ductility level of 3-4.

Any contribution of infill wall stiffness to out-of-plane action is neglected.

\section{Relationship between stiffness and floor area ratios of lateral load bearing members}

Equations (9), (11) and (12) relate sectional properties to member detailing; thus, translational member stiffnesses given by Eqs. (10) and (13) are expressed as multiples of the 
corresponding axial rigidities of the members, $E_{c} A_{J} / h_{i}, E_{c} A_{b} / h_{i}, E_{c} A_{w} / h_{i}$; the same is true by definition for the infill stiffness contribution, Eq. (14). These terms are modified further, by replacing the cross-sectional area terms, $A_{J}, A_{b}, A_{w}, A_{m w}$, with area ratios of vertical members, referred to the floor plan area, $A_{f l}$ (Gülkan and Sozen, 1996): $A_{J}=\rho_{J} A_{f l}, A_{b}=\rho_{b} A_{f l}, A_{w}=\rho_{w} A_{f l}$, $A_{m w}=\rho_{m w} A_{f l}$. A general expression is thus derived from first principles for the entire storey stiffness:

$$
\begin{aligned}
& K_{i} \cdot \Delta \Phi_{i} \cdot \delta \Delta \Phi_{i}= \\
& \underbrace{\left\{\ell_{b} K_{j}^{b} \cdot \Delta \Phi_{j} \cdot \delta \Delta \Phi_{j}\right\}}_{\ell_{b} \text { floor beams }}+\underbrace{\left\{\sum_{j=l}^{\ell_{c}} K_{j}^{J, c} \cdot \Delta \Phi_{j} \cdot \delta \Delta \Phi_{j}\right\}}_{\ell_{c} \text { floor columns }}+\underbrace{\left\{\sum_{j=1}^{\ell_{w}} K_{j}^{w} \cdot \Delta \Phi_{j} \cdot \delta \Delta \Phi_{j}\right\}_{i}}_{\ell_{w} \text { walls in floor }}+\underbrace{\left\{\sum_{j=l}^{\ell_{m w}} K_{j}^{m w} \cdot \Delta \Phi_{j} \cdot \delta \Delta \Phi_{j}\right\}}_{\ell_{m w} \text { masonry infills in floor }}
\end{aligned}
$$

which is simplified further to:

$$
\begin{aligned}
& K_{i} \cdot \Delta \Phi_{i} \cdot \delta \Delta \Phi_{i}=\frac{E_{c} A_{f l}}{h_{i}} \Omega_{i} \cdot \Delta \Phi_{i} \cdot \delta \Delta \Phi_{i}= \\
& \frac{E_{c} A_{f l}}{h_{i}}\left(\lambda_{c}^{2}\left\{\sum_{j=l}^{\ell_{c}} \Omega_{j}^{J} \cdot \Delta \Phi_{j} \cdot \delta \Delta \Phi_{j}\right\}_{i}+\left\{\sum_{j=l}^{\ell_{w}} \Omega_{j}^{w} \cdot \Delta \Phi_{j} \cdot \delta \Delta \Phi_{j}\right\}_{i}+\left\{\frac{0.1 \cdot f_{w k}}{\mu_{y}^{m w} \theta_{y}^{m w} E_{c}} \sum_{j=l}^{\ell_{m}} \Omega_{j}^{m w} \cdot \Delta \Phi_{j} \cdot \delta \Delta \Phi_{j}\right\}_{i}\right)
\end{aligned}
$$

where:

$$
\begin{aligned}
& \lambda_{c}^{2}\left\{\sum_{j=1}^{\ell_{c}} \Omega_{j}^{J} \cdot \Delta \Phi_{i} \cdot \delta \Delta \Phi_{i}\right\}_{i}=\left(1-\lambda_{c}\right)^{2}\left\{\sum_{j=1}^{\ell_{b}} \Omega_{j}^{b} \cdot \Delta \Phi_{i} \cdot \delta \Delta \Phi_{i}\right\}_{i}+\lambda_{c}^{2}\left\{\sum_{j=1}^{\ell_{c}} \Omega_{j}^{J, c} \cdot \Delta \Phi_{i} \cdot \delta \Delta \Phi_{i}\right\}_{i} \\
& \sum_{j=1}^{\ell_{b}} \Omega_{j}^{b} \cdot \Delta \Phi_{i} \cdot \delta \Delta \Phi_{i}=\frac{\alpha_{c, b}}{h_{i}} \sum_{j=1}^{\ell_{b}}\left(\frac{\rho_{b, j} d_{b, j}^{2} i_{b, j}}{L_{b, j}}\right) ; \sum_{j=1}^{\ell_{b}} K_{j}^{b} \cdot \Delta \Phi_{i} \cdot \delta \Delta \Phi_{i}=\lambda_{b}^{2} \sum_{j=1}^{\ell_{b}} \Omega_{j}^{b} \cdot \Delta \Phi_{i} \cdot \delta \Delta \Phi_{i} \\
& \sum_{j=1}^{\ell_{c}} \Omega_{j}^{J, c} \cdot \Delta \Phi_{i} \cdot \delta \Delta \Phi_{i}=\frac{\alpha_{c, J}}{h_{i}^{2}} \sum_{j=1}^{\ell_{c}}\left(\rho_{J, j} d_{J, j}^{2} i_{J, j}\right) ; \sum_{j=1}^{\ell_{c}} K_{j}^{J, c} \cdot \Delta \Phi_{i} \cdot \delta \Delta \Phi_{i}=\lambda_{c}^{2} \frac{E_{c} A_{f l}}{h_{i}} \sum_{j=1}^{\ell_{c}} \Omega_{j}^{J, c} \cdot \Delta \Phi_{i} \cdot \delta \Delta \Phi_{i} \\
& \ell_{w} \Omega_{j}^{w} \cdot \Delta \Phi_{i} \cdot \delta \Delta \Phi_{i}=\sum_{j=1}^{\ell_{w}} \frac{\rho_{w, j} d_{w, j}^{2}}{\left(1+\beta_{j}\right)} i_{w, j}\left\{4 \Theta_{w, j}^{A}+\beta \Theta_{w, j}^{B}\right\} ; \sum_{j=1}^{\ell_{w}} K_{j}^{w} \cdot \Delta \Phi_{i} \cdot \delta \Delta \Phi_{i}=\frac{E_{c} A_{f l} \ell_{w}}{h_{i}} \sum_{j=1}^{w} \Omega_{j}^{w} \cdot \Delta \Phi_{i} \cdot \delta \Delta \Phi_{i}
\end{aligned}
$$

Beam contribution to stiffness in flexural-type wall structures is neglected in the remainder, for simplicity. For masonry infills: 


$$
\sum_{j=1}^{\ell_{m w}} \Omega_{j}^{m w} \cdot \Delta \Phi_{i} \cdot \delta \Delta \Phi_{i}=\sum_{j=1}^{\ell_{m w}}\left(1+\frac{h_{i}^{2}}{l_{m w, j}^{2}}\right)^{0.5} \rho_{m w, j} ; \sum_{j=1}^{\ell_{m w}} K_{j}^{m w} \cdot \Delta \Phi_{i} \cdot \delta \Delta \Phi_{i}=\frac{E_{c} A_{f l}}{h_{i}} \cdot \frac{0.1 \cdot f_{w k}}{\mu_{y}^{m w} \theta_{y}^{m w} E_{c}} \sum_{j=1}^{\ell_{m w}} \Omega_{j}^{m w} \cdot \Delta \Phi_{i} \cdot \delta \Delta \Phi_{i}
$$

Terms $\Omega^{b}, \Omega^{J, c}, \Omega^{w}$ and $\Omega^{m w}$ control the stiffness of a particular floor and are parametrically related to the characteristics of the global intervention considered and the materials used. For simplicity in preliminary retrofit design, and to limit the degrees of freedom in decision making, it is possible to initially neglect the influence of beams, by setting the corresponding $\lambda$ parameters in Eq. (17a) equal to: $\lambda_{b}=0, \lambda_{c}=1$, i.e. $\Omega_{J}=\Omega_{J, c}$. This option will generally overestimate the contribution of the vertical members to stiffness, thereby numerically compensating for the neglected contribution of the beams (in the retrofitted structure, $\left.\Omega^{I, b}<\Omega^{I, c}\right)$. The stiffness level specified by the retrofit strategy may be provided by various combinations of the three types of global intervention considered; other types of interventions may be also used, depending on the basic stiffness value supplied by the existing frame.

\section{INTERSTOREY DRIFT SPECTRA (IDS)}

The elastic spectrum of Eurocode 8 (Type I, EC8-I 2004) is used herein to represent the design seismic hazard with no loss of generality. Demand in terms of spectral displacement is defined by Eq. (18) for the period range of practical interest $(\mathrm{T} \leq 2 \mathrm{sec})$ and an example scenario: soil type $\mathrm{B}$, high seismicity region $\left(\alpha_{g}=0.36 \mathrm{~g}\right)$, parameter values $S=1.2, q=1$ and $T_{B}=0.15, T_{C}=0.50$ and $T_{D}=2.00 \mathrm{sec}:$

$$
\begin{gathered}
0.15 \leq T \leq 0.50: \quad \mathrm{S}_{d}(T)=0.0273 g T^{2} \\
0.50<T \leq 2.00: \quad \mathrm{S}_{d}(T)=0.0137 g T
\end{gathered}
$$

The corresponding elastic value of the $i^{\text {th }}$ storey interstorey-drift, $I D_{i}$, is given by: 
$I D_{i}=\frac{\left(\Phi_{i}-\Phi_{i-1}\right)}{h_{i}} \Delta_{i}=\frac{\Delta \Phi_{i}}{h_{i}} \frac{L^{*}}{M^{*}} S_{d i}$

For any chosen target response shape, values of $L^{*}, M^{*}$ calculated from Eq. (1) are substituted in Eq. (19) to extract expressions for the elastic IDS. In frame structures, the column share of the elastic interstorey drift is $I D_{i}{ }^{c}=\lambda_{c} \cdot I D_{i}$, whereas the corresponding beam share is $I D_{i}^{b}=\lambda_{b} \cdot I D_{\mathrm{i}}$.

Assuming that the critical storey is the first storey (ground floor, with a typical storey height $h_{i}=3 \mathrm{~m}$ ) the general form for the elastic interstorey drift of the first storey, $I D_{l}$, is (Units in ton, $\mathrm{kN}, \mathrm{m}$ ):

$$
\begin{aligned}
& 0.15 \leq T \leq 0.50: I D_{1}=31.78 \frac{\Phi_{1}}{h_{1}} B_{1} \cdot \frac{m}{E_{c} A_{f l}} \cdot \frac{1}{\Omega_{1}} \\
& 0.50<T \leq 2.00: I D_{1}=1.46 \frac{\Phi_{1}}{h_{1}} B_{1} B_{2}^{-0.5}\left(\frac{m}{E_{c} A_{f l}}\right)^{0.5} \frac{1}{\Omega_{1}^{0.5}}
\end{aligned}
$$

where $\Omega_{1}$ is the stiffness term of the first storey given by the sum of terms $\Omega^{I}, \Omega^{w}$ and $\Omega^{n w}$ according to Eq. (16). Parameters $B_{1}$ and $B_{2}$ are defined as:

$$
B_{1}=\frac{\sum_{i=1}^{n} \Phi_{i}}{\sum_{i=1}^{n} \kappa_{i} \cdot\left(\Delta \Phi_{i}\right)^{2}} ; B_{2}=\frac{\sum_{i=1}^{n} \Phi_{i}^{2}}{\sum_{i=1}^{n} \kappa_{i} \cdot\left(\Delta \Phi_{i}\right)^{2}}
$$

Values of parameters $B_{1}, B_{2}$ and $\Phi_{1} / h_{1}$ are plotted in Fig. 8 for three alternative target response shapes (triangular, trigonometric with shear and with flexural type characteristics).

Figure 9 plots diagrams that relate the elastic drift demand of the first storey with the stiffness coefficient of the first storey, $\Omega_{1}$, according to Eqs. (20) for the triangular, shear and flexural response profiles and for 2- up to 8-storey buildings. These design charts define the unique relationship between elastic drift level and stiffness demand in the first storey (the stiffness of the upper storeys may be determined from Fig. 3 or from the expressions of Table 1). The target interstorey drift, $I D_{y, \text { target, },}$, is defined by dividing the elastic interstorey drift by 
the behavior factor, $q$ ( $q=\mu$ in the higher range of periods except for low periods). Thus, for a known number of storeys, using the target drift level of the first storey as the sole input to the retrofit design algorithm, the demand in stiffness of the first storey is obtained directly. It is observed that in case of the triangular and the shear response profiles, for drift levels equal to $1.5 \%$ or higher, and for buildings higher than three storeys, the stiffness of the first storey is insensitive to the number of storeys. Also note that for the flexural response shape, the building's aspect ratio is reflected in the value of the stiffness demand estimate of the first floor (this value is reduced after a number of floors as the building geometry becomes more slender tending naturally towards a flexural-type response).

Application of the proposed method is demonstrated in the last section of the paper through an example case study.

The stiffness coefficient of the first storey, $\Omega_{1}$, comprises individual stiffness contributions ( $\Omega_{1}{ }^{J}$ and $\Omega_{1}{ }^{w}$ or $\Omega_{1}{ }^{m w}$ ) according to Eq. (16), depending on the combination of the GI methods chosen. Mathematically, Eqs. (20) represent equations of the type, $\mathrm{a}_{1} \mathrm{x}_{1}+\mathrm{a}_{2} \mathrm{x}_{2}=\mathrm{C}_{1}, \mathrm{a}_{1} \mathrm{x}_{1}+\mathrm{a}_{2} \mathrm{x}_{2}+\mathrm{a}_{3} \mathrm{x}_{3}=\mathrm{C}_{2}$ where the constant term $\mathrm{C}_{1}$, or $\mathrm{C}_{2}$, depends on the drift level considered as depicted schematically in Fig. 10(a). The plots of Fig. 10(a) are referred to hereon as Interstorey Drift Spectra $(I D S)$. They provide all possible combinations of $\left(\Omega^{\prime}\right.$, $\left.\Omega^{w}, \Omega^{n w}\right)$ values that satisfy the elastic drift level under the specified design earthquake. In practice, it is uncommon to use all three GI methods simultaneously and the 2D plot (Fig. 10(b)) appears more applicable. The IDS of a 3-storey frame building that responds according to a shear profile is shown in Fig. 10(b). In this application, the contribution of the infill masonry walls has been neglected $\left(\Omega^{m w}=0\right)$ and parameter $\lambda_{c}$ has been taken equal 1 to simplify the preliminary retrofit process as discussed in the preceding.

Similar IDS may be developed using the same procedures for any global intervention method, provided that the elastic stiffness may be expressed explicitly in terms of the 
technological parameters of that intervention (using the same steps as done herein for jackets, walls and infills.)

\section{PRACTICAL RETROFIT DESIGN}

Performance objectives are set with reference to yielding of the retrofitted structural members (e.g. ductility demand associated with the YPS used). Thus, in designing the retrofit scheme with the proposed methodology the engineer selects: (1) the target interstorey drift at yield of the first storey, $I D_{y, \text { target, }, \text {, }}(2)$ the target response shape, $\Phi$, and (3) the target ductility demand, $\mu_{\text {target }}$ (i.e. performance of the retrofitted structure is considered in the inelastic stage of response). The construction of the IDS follows (Fig. 10), where the target interstorey drift at yield of the first storey, $I D_{y, \text { target, },}$, is related to the corresponding stiffness demand in terms of $\Omega^{J}, \Omega^{w}$ and $\Omega^{m w}$ drawn using the results of Eqs. (20); here, for demonstration, three alternatives for the selected target response shape are considered. Numerous combinations for the stiffness parameters are possible, depending on the target interstorey drift at yield of the first storey, $I D_{y, \text { target } 1}$.

The lower the $I D_{y, \text { target, },}$, the higher the level of required strengthening, leading to a further reduction in the period value. The demand for an ESDOF in the ADRS Spectrum format is given by the radial line with a slope of $4 \pi^{2} / T^{2}$, where $T$ is the system's period. Thus, the changes effected in the period as a result of the alternative retrofit solutions may be readily inspected by this geometric parameter (i.e. the slope of the radial line).

The required floor stiffnesses $\Omega^{J, c}, \Omega^{w}$ and $\Omega^{m w}$ thus determined, are then distributed to the floor vertical members at ratios proportional to gross section properties. Flexible columns of the lateral load resisting system (i.e., members with a sway index $>30$ ) or columns with a high axial load ratio $(v>0.3)$ are primary candidates for stiffness enhancement; alternatively, all required stiffness addition may be provided by addition of RC walls or infills. 
Each member is designed in the retrofit scheme to satisfy the targeted interstory drift at yield (for columns: $I D_{y, \text { target }, 1}{ }^{c}=\lambda_{c} \cdot I D_{y, \text { target }, 1}$ ) and to provide the required stiffness as defined through the $\Omega^{J, c}, \Omega^{w}$ and $\Omega^{m w}$ coefficients (Eqs. (17)). For the j-th member of the i-th floor, given the drift or rotation at yielding $\left(I D_{y, i}\right)$, the corresponding curvature demand value (reinforcement slip owing to bond included), $\varphi_{y, j}$, is calculated from $\varphi_{y, j}=$ $I D_{y, i} /\left[0.167\left(h_{i}+0.125 D_{b} f_{y} / f_{b y}\right)\right]$ (Paulay and Priestley 1992). The associated normalized depth of compression zone $\xi_{j}$ is obtained by virtue of definition of $\varphi_{y, j}$. Required longitudinal reinforcing ratios are obtained from the design charts of Figs. 6(b), 7(b), for known $\xi$ and $v$ values.

\section{Verification of member ductility demand}

After dimensioning and detailing, the available drift capacity may be evaluated for each retrofitted member, for the purposes of verification of the retrofit design. Assuming that all premature failure modes but flexural are suppressed through local interventions at the member level (e.g., through jacketing with composite wraps, and by capacity-designing transverse reinforcement in the $\mathrm{RC}$ jacketed columns), the ultimate curvature demand is expressed in terms of the member's displacement ductility demand, $\mu$ (Paulay and Priestley 1992):

$$
\varphi_{u, j}=0.333 \varphi_{y, j}(\mu-1) \frac{h_{i}}{h_{J}}+\varphi_{y, j}
$$

The solution scheme is acceptable when the ultimate curvature capacity of the member $\left(\phi_{u, j}=\varepsilon_{c u} / \xi_{u} d\right)$ exceeds the estimate of Eq. (22) ( $\varepsilon_{c u}$ is the strain capacity of the member's compression zone). 


\section{SCOPE AND LIMITATIONS OF THE PROPOSED FRAMEWORK}

Relevant issues or precautions related to the scope, limitations and applicability of the proposed retrofit framework are the following:

Scope: The proposed method is not intended to replace or substitute detailed modeling of the rehabilitated structure; rather, post-design performance verification checks should be done, whenever possible, through time history analysis of a robust structural model of the structure after the rehabilitation design has been finalized. The proposed framework is meant to address the needs of preliminary design, namely to provide a test-bed for fast assessment of alternative retrofit schemes. The method uses a spectrum-based description of the design earthquake. Therefore, it necessarily relies on an equivalent single degree of freedom representation of the structure. Other considerations also apply in determining the applicability of a SDOF-based approach as opposed to detailed Finite Element Modeling (FEM) for preliminary design, such as, budgetary limitations, lack of detailed drawings of the original old structure (a frequent occasion in many regions of the world), but also in the presence of obvious deficiencies that identify a single mechanism formation (such as soft storeys).

Limitations: Although the emphasis is on the secant-to-yield stiffness, strength is the underlying parameter due to the implicit relationship between stiffness and strength in RC members. Thus, the reverse enforcement of a target fundamental response pattern basically regulates the strength distribution throughout the building, by exploiting the stiffness to strength relationship. This is why the analysis is conducted with reference to the yield point (end of the elastic branch) in the response curve of the rehabilitated structure. However, this does not imply that response of the rehabilitated structure to the design earthquake is to remain elastic - rather, through the use of the YPS, the choice of stiffness/strength pattern also determines immediately the targeted ductility demand, $\mu_{\text {target }}$, that will be imposed on the 
rehabilitated structure by the design earthquake. Considering that nonlinear behavior of the retrofit is often limited by the existing reinforcement anchorages, which may remain a weak zone of behavior even after rehabilitation, it is generally advisable that the ductility demand targeted for through the choice of the design YPS should not exceed the value of 3 (i.e., it should be required that $\Delta_{u}<3 \Delta_{y}$ ) (EC8-I 2004, KANEPE 2010); this limit refers to the structural system. Having eliminated the risk of localization through proper selection of the target response shape, individual target member rotation demand is given by:

Column: $I D_{y, \text { targ et,i }}^{c}=\lambda_{c} \frac{\Delta \Phi_{i}}{h_{i}} \frac{L^{*}}{M^{*}} \frac{S_{d, i}}{q} \underline{\text { Beams: }} I D_{y, \text { targ } e t, i}^{b}=\lambda_{b} \frac{\Delta \Phi_{i}}{h_{i}} \frac{L^{*}}{M^{*}} \frac{S_{d, i}}{q}$

Performance verification checks of the individual members as well as for the structural system should satisfy at least these determined displacement ductility demand values.

Higher Mode Participation: Although the preliminary design of the retrofit scheme proposed herein focuses in the fundamental mode of behavior as a basic diagnostic tool, actual dynamic response of the retrofitted structure may contain, under conditions, a significant contribution of higher modes (particularly in the case of taller structures). Implications of these effects on the internal force distribution should be quantified at the stage of performance verification of the retrofit design.

Connection to the horizontal diaphragms: Global interventions (GI's) aimed at modifying the translational stiffness of the structure as a whole, increase the degree of engagement of horizontal elements; in older structures two types of horizontal diaphragms are usually found: (a) Slabs on beams (e.g. Southern Europe), where beams are part of a well defined albeit brittle, lateral load resisting frame; in these cases, beams are usually stronger than the columns, whereas this hierarchy is expected to be reversed after the implementation of GI's such as those proposed herein. (b) Flat plates (e.g. in North America); these structures often 
have a large sway index, and their most vulnerable regions are in the slab-column connection areas, whereas they often lack a well-defined collector system (continuous struts and ties in the horizontal diaphragms to enable transfer of forces). In either case, horizontal diaphragms are expected to develop yielding at the connections after retrofit. Therefore, local interventions to preclude connection failure and to ensure post-yield deformation capacity in the horizontal beams or flat plates should be designed for in order for the members to pass the necessary performance verification checks during assessment of the retrofit. Examples are the addition of transverse reinforcement in beams to improve anchorage of primary reinforcement and elimination of shear failure and post-installed studs or drop-panels in flat plate connections to eliminate the risk of punching. It may generally be stated, however, that the most effective measure for eliminating the risk of connection failure is through reduction of the imposed deformation demand, and thus, by stiffening the vertical members, the proposed rehabilitation framework is consistent with this objective.

\section{EXAMPLE: IMPLEMENTATION OF THE PROPOSED METHODOLOGY}

\section{Description of the frame structure}

The proposed methodology is applied to a four-storey four-bay frame designed according with the prevailing practice of Southern Europe in the 1970's (Fig. 11). Provisions for seismic detailing and inelastic energy dissipation in the 70's (DIN 1045 1972) were lenient as compared to modern standards Although this is an analytical case study, details and geometry of the frame are typical examples of actual medium rise residential structures that experienced non-repairable damage or collapse during the 1999 Athens Earthquake. Member details and material properties are listed in Fig. 11. 


\section{Alternative retrofit options}

Raleigh-type iteration of the existing frame assuming rigid diaphragms led to a period estimate of $1.66 \mathrm{sec}$ and a translational mode $\Phi^{\mathrm{T}}=[0.27,0.56,0.82,1.00]^{\mathrm{T}}$. To reduce the period to a value near the $0.4 \mathrm{sec}$ empirical limit for a four-storey frame, strengthening was considered using two alternative retrofit strategies. The first one, referred to hereon as RS1, aims at strengthening the existing frame while maintaining, albeit improving the shear-type response profile (Fig. 12(a)). The second retrofit scenario, (RS2), aims at altering the fundamental mode of the frame towards a flexural-type (Fig. 12(b)). This is accomplished by infilling the two external bays ( $2 \mathrm{~m}$ spans) while RC jacketing the middle row of columns. In both approaches the contribution of infill masonry walls to the floor stiffness was neglected (by setting the term $\Omega^{m w}=0$ ). In the case of the RS1 retrofit solution the influence of the contribution of beams to the floor stiffness was estimated according with Eq. 17(a) through parameters $\lambda_{c}$ and $\lambda_{b}$.

\section{(1) RS1: Retrofit by RC column jacketing}

This retrofit scenario aims at a significant period reduction and a uniform distribution of interstorey drift (i.e., triangular target response shape, $\Phi^{T}=[0.25,0.50,0.75,1.00]^{T}$ ) by $\mathrm{RC}$ jacketing all the vertical members along the height of the building with a $50 \mathrm{~mm}$ thick jacket layer (i.e., final column dimensions were increased to 350x350mm, Fig. 12(a)). All members of the same floor participate in the lateral resistance of the structure by the same $\Delta \Phi_{i}$ value. The EC8-I Type I (2004) earthquake design hazard was used to define demand (Fig. 13(a)); this was expressed by the Y.P.S. obtained using the equal displacement rule $(q=\mu)$. Each radial line corresponds to a period value and indirectly to a stiffness value related to a specific drift at yield of the first storey of the retrofitted building.

Aiming at a target drift at yield of the first storey equal to $I D_{y, \text { target }, I}=0.50 \%$, with a ductility demand limited to $\mu_{\text {target }}=2\left(1.00 \%\right.$ curve in the IDS of Fig. 13(b) for $\left.\Omega_{1}{ }^{w}=0\right)$, the 
required stiffness coefficient is equal to $\Omega_{l}=\lambda_{c}{ }^{2} \Omega_{l}{ }^{J}=8.52 \times 10^{-5}$ (Eq. 20(a)). The stiffness demand of the first storey is calculated according to Eq. (16) and is equal to $K_{l}=E_{c} A_{f l} / h_{l} \cdot \Omega_{l}=52710 \mathrm{kN} / \mathrm{m} \quad$ (where $E_{c}=29 \cdot 10^{6} \quad \mathrm{kN} / \mathrm{m}^{2}, \quad A_{f l}=64 \mathrm{~m}^{2}, \quad h_{l}=3 \mathrm{~m}$ ) which corresponds to target period $T_{\text {target }}\left(=2 \pi \sqrt{ }\left(m B_{2} / K_{l}\right)=0.67 \mathrm{sec}\right.$ (where $m=60.1 \mathrm{kN} /\left(\mathrm{m} / \mathrm{sec}^{2}\right)$, $B_{2}=10, K_{l}=52710 \mathrm{kN} / \mathrm{m}$ ) (Fig. 13(a)). Assuming that the cracked stiffness is equal to $50 \%$ of the elastic stiffness (EC8-I 2004), then the average $\lambda$ factors for columns and beams are $\lambda_{c}=0.7$ and $\lambda_{b}=0.3$, respectively, whereas stiffness coefficient for beams is estimated equal to $\Omega_{l}^{J, b}\left(=12 /\left(h_{1} A_{f l}\right) \cdot \Sigma\left(I_{c r, i} / L_{b, i}\right)\right)=1.60 \times 10^{-4}$. According to Eq. $17(\mathrm{a})$, the vertical members of the first storey should be strengthened to reach a stiffness coefficient equal to $\Omega_{1}{ }^{J, c}=1.42 \times 10^{-4}$ $\left(\lambda_{c}^{2} \Omega_{1}^{J, c}=7.18 \times 10^{-5}<8.52 \times 10^{-5}\right)$. Depending on the assumption made for the estimation of the cracked stiffness, factors $\lambda_{c}$ and $\lambda_{b}$ may be modified leading to a different distribution of stiffness between the vertical and horizontal structural members. For the sake of simplicity, the following calculations are performed for $\lambda_{c}=1\left(\operatorname{target} \Omega_{l}=\Omega_{l}{ }^{J}=8.52 \times 10^{-5}\right)$. This hypothesis leads to an overestimation of the stiffness provided by the strengthened vertical members by $15 \%$ which is considered acceptable for the phase of preliminary design. Factors $\lambda_{c}, \lambda_{b}$, are assessed at the post-retrofit design phase where the geometry and reinforcing detailing of the members is known.

The vertical members of the first storey are designed for target stiffness $K_{l}=52710$ $\mathrm{kN} / \mathrm{m}$, whereas the target stiffness of the other storeys is estimated from Fig. 3(a) by taking into account the stiffness ratios, $\kappa_{i}\left(K_{2}=47439 \mathrm{kN} / \mathrm{m}, K_{3}=36897 \mathrm{kN} / \mathrm{m}, K_{4}=21084 \mathrm{kN} / \mathrm{m}\right)$. The target stiffness of each storey is equally distributed to the five columns of the storey (Table 2).

A note of caution is that detailing of the retrofitted cross-sections ought to comply with code provisions (regarding minimum bar diameter, minimum longitudinal reinforcement ratio and minimum jacket thickness) and therefore deviations from the target shape may be imperative due to code or construction limitations. Here, the required reinforcement for 
jackets of $1 \%$ in the $4^{\text {th- }}$ storey columns is subject to the code's restriction for minimum distance between longitudinal reinforcement and bar diameter. This led to an increased stiffness of the typical fourth storey column (instead of $4217 \mathrm{kN} / \mathrm{m}$ to $6051 \mathrm{kN} / \mathrm{m}$ ).

\section{(2) RS2: RC infill walls and selective RC column jacketing}

The second retrofit scenario aims at a fundamental change of the response of the frame by creating a dual lateral load resisting system (addition of two infill walls in the external bays incorporating the existing columns, RC jacketing of the interior row of columns (Fig. 12(b)). Behavior of the retrofitted structure is influenced greatly by the presence of the infill RC walls and for this reason it is assumed at the onset of the retrofit design that the target response profile would be closer to the flexural type. The EC8-I Type I (2004) earthquake design hazard was used again to define demand (Fig. 13(a)).

The retrofit scenario aims at an average target interstorey drift at yield for the dual system equal to $0.25 \%$ (to account for the fact that dual systems with walls yield at a lower drift, around $0.2-0.25 \%)$. According to the flexural profile distribution $(\Phi(z)=1-\cos (\pi z /(2 h n))$, (Fig. 2(c)), this corresponds to an interstorey drift distribution along the height of the building equal to: first storey $I D_{y, \text { target, } 1}=0.075 \%$, second storey $I D_{y, \text { target }, 2}=0.21 \%$, third storey $I D_{y, \text { target }, 3}=0.32 \%$ and fourth storey $I D_{y, \text { target }, 4}=0.38 \%$. For a ductility demand limited to $\mu_{\text {target }}=2$, demand in terms of the stiffness coefficient is defined from the IDS (Fig. 13(c)) for $I D=0.15 \%=2 \times 0.075 \%: \Omega_{l}=\left(\Omega_{l}{ }^{J}+\Omega_{l}{ }^{w}\right)=61.3 \times 10^{-5}$ (Eq. $20($ a) $)$. The stiffness demand of the first storey is calculated according to Eq. (16) and is equal to $K_{l}=E_{c} A_{f l} / h_{l} \cdot \Omega_{I}=379243 \mathrm{kN} / \mathrm{m}$ (where $E_{c}=29 \cdot 10^{6} \mathrm{kN} / \mathrm{m}^{2}, A_{f l}=64 \mathrm{~m}^{2}, h_{l}=3 \mathrm{~m}$ ) which corresponds to target period $T_{\text {target }}\left(=2 \pi \sqrt{ }\left(m B_{2} / K_{l}\right)=0.40 \mathrm{sec}\right.$ (where $\left.m=60.1 \mathrm{kN} /\left(\mathrm{m} / \mathrm{sec}^{2}\right), B_{2}=26, K_{l}=379243 \mathrm{kN}\right)$ (Fig. 13(a)).

The target stiffness of the other storeys is estimated from Fig. 3(c) by taking into account the stiffness ratios, $\kappa_{i}\left(K_{2}=128069 \mathrm{kN} / \mathrm{m}, K_{3}=72452 \mathrm{kN} / \mathrm{m}, K_{4}=37978 \mathrm{kN} / \mathrm{m}\right)$. 
Assuming that the target stiffness of the interior row of columns is identical with that of the previous solution $(\mathrm{RS} 1) K_{l}{ }^{J}=52710 / 5=10542 \mathrm{kN} / \mathrm{m}$ (i.e. according to Eq. (16): $\Omega_{l}{ }^{J}=1.73 \times 10^{-}$ ${ }^{5}$ ) and that cross-sectional detailing follows that of Table 2, each wall is designed for $K_{l}{ }^{w}=184351 \mathrm{kN} / \mathrm{m}\left(\Omega_{l}{ }^{w}=\left(61.3 \times 10^{-5}-1.73 \times 10^{-5}\right) / 2=59.5 \times 10^{-5} / 2=29.8 \times 10^{-5}\right)$. The geometry and reinforcement details of the wall remain the same along the height of the building (the term $E_{c} I_{y, j}{ }^{w} / h_{i}$ of Eq. (5) is constant, whereas the reduction of stiffness of the upper floors is attributed to the difference in deformation defined by the term $\left\{4 \Theta_{w, j}{ }^{A}+\beta_{j} \Theta_{w, j}{ }^{B}\right\} /\left(1+\beta_{j}\right)$ of Eq. 5). Details of wall design are depicted in Fig. 12(b). Boundary elements comprise the existing columns $(250 \times 250 \mathrm{~mm}$, long. reinf. 4Ø14, stirrups $\varnothing 6 / 250)$ and a new rectangular crosssection $250 \times 300 \mathrm{~mm}$, with longitudinal reinforcement $6 \varnothing 18$, stirrups $\varnothing 10 / 100$, web vertical reinforcement $\varnothing 12 / 100$ and web horizontal reinforcement $\varnothing 12 / 200$ (Fig. 12(b)).

\section{Post-retrofit assessment}

Models of the retrofitted frames were constructed in the environment of ZeusNL, a nonlinear finite element analysis platform (Elnashai et al. 2002).

Pushover analysis: Inelastic static pushover analyses were performed for a target drift at ultimate equal to $3.5 \%$ of the building height (target lateral displacement at the top: $420 \mathrm{~mm}$ ), with the exception of the existing frame case, where analysis was terminated at a drift of $1.4 \%$ (=168 $\mathrm{mm}$ top lateral displacement, at $20 \%$ strength loss). The response of the retrofitted frame solutions is plotted against the response of the original frame in Fig. 14(a). A fundamental modification of the response is effected by both retrofit solutions considered in terms of stiffness, strength and deformation capacity.

Distribution of plastic-hinge formation at member ends are illustrated in Figs. 14(c) and (d) for two drift levels $(0.5 \%$, and $1.0 \%)$ for the RS1 and RS2 retrofit solutions, respectively. It is observed that both retrofit options adopted have changed the sequence of 
plastic hinge formation as compared with the existing frame (Fig. 14(b)), leading to a more desirable pattern with plastic hinges distributed along the beam ends in the retrofitted structures and eliminating mechanism formations (i.e., simultaneous plastic hinges in both columns ends in a single floor).

Dynamic time-history analysis: Behavior of the retrofitted frames was assessed by performing inelastic time history analyses for a group of artificial records used in the fullscale test of the ICONS frame (Pinto et al. 2002) which are representative of a moderatelyhigh European seismic hazard scenario; the El-Centro ground motion (ELC180 1940) was also used. The duration of significant excitation in the artificial records was around $15 \mathrm{sec}$ and the peak ground acceleration was $0.22 \mathrm{~g}, 0.29 \mathrm{~g}$ and $0.38 \mathrm{~g}$, for the 475,975 and 2000 year return events, respectively. The total duration of the El Centro record (ELC180 1940) was 40 $\mathrm{sec}$ and the peak ground acceleration was $0.31 \mathrm{~g}$. In the following, the return period is used as an identification code for the artificial record considered.

Storey displacement time histories and the corresponding displacement profiles are plotted in Figs. 15 and 16 for the two alternative retrofit solutions (RS1 and RS2), subjected to the four ground motion records. In the storey displacement profile diagrams of Fig. 15, the black solid curve, which corresponds to the post-design fundamental response shape of the RS1 retrofit solution, is compared against the dynamic response storey profiles (group of gray colored curves) corresponding to points of peak roof displacement response obtained under the various ground motions (different intensity) that were considered in the evaluation. The post-design fundamental response shape is estimated from Rayleigh iteration (Clough and Penzien 1993) taking into account the contribution of the beams and the revised $\lambda$ factors $\left(\lambda_{c}=0.4, \lambda_{b}=0.6\right)$ in the method's calculation of strain energy at yield. (The strain energy stored in the structure when it vibrates in its fundamental response shape is: 
$U_{E}=\frac{1}{2} \cdot \sum_{i=1}^{n}\left[\lambda_{b}^{2} \sum_{j=1}^{\ell_{b}} \frac{\alpha_{c, b} E_{c} I_{y, j}^{b}}{L_{b, j} h_{i}^{2}}+\lambda_{c}^{2} \sum_{j=l}^{\ell_{c}} \frac{\alpha_{c, J} E_{c} I_{y, j}^{J}}{h_{i}^{3}}\right] \cdot \Delta \Phi_{i}^{2} \cdot Z_{\max }^{2}$

using secant to yield measures for member flexural stiffness properties). The post-design fundamental shape actually serves as a lower bound to the actual response profile. With advancing nonlinearity, the effective $\lambda$ goes further down tending to 0 (since the plastic hinges are located in beams, $\lambda_{b}=0$ ) thereby rendering the structure more "flexural", as is evident also in the latter deflection profiles in Fig. 15.

In case of the RS2 option the displacement response profiles (gray lines) ranged between the triangular and the flexural target response shapes (Fig. 16) and in most cases were bundled between an average (of the flexural and the triangular) and the triangular target shape. This indicates that the response of the resulting dual system was moderated as compared to a purely wall-type solution.

Additional information regarding the comparison of lateral displacement and interstorey drift profiles between the existing frame and the retrofitted ones are depicted in Figs. 17 and 18 for RS1 and RS2, respectively. Both retrofit solutions are quite effective in modifying the response shape and providing an almost uniform distribution of interstorey drift along the height of the building.

The maximum drift, $I D$, attained by the existing frame and each retrofit solution under the four ground motions is presented in Table 3. The presence of walls controlled the lateral displacement of the building significantly (Table 3 ).

Yield Point Spectra: The retrofit solutions are assessed by using the Yield Point Spectra (Aschheim and Black 2000) for the El Centro ground motion and the EC8-I design spectra. In case of the El Centro ground motion, ductility demand for retrofit solutions RS1 and RS2 is equal to 1.25 and 1.07, respectively (Fig. 19(a)). The ductility demand imposed by the EC8-I 
(2004) design spectrum (the retrofit solutions were designed according to it) is 2.0 for RS1 and 1.2 for RS2 (Fig. 19(b)) thereby verifying realization of the retrofit strategy's objectives.

\section{SUMMARY AND CONCLUSIONS}

A displacement-based design methodology for development of the rehabilitation strategy of existing RC buildings was presented. Central concept of the proposed retrofit strategy was modifying the stiffness distribution so as to match a predefined target fundamental response shape. This target profile effectively serves as a first order approximation; the final mode shape may deviate somewhat from the targeted one. Interstorey Drift Spectra (IDS) were derived and practical design charts were established to readily relate the technological characteristics of well-known global intervention methods to drift demands. Stiffness required in order to limit drift within acceptable levels was obtained from the IDS. The methodology was tested in an example case study of a four-storey four-bay frame where two alternative retrofit strategies were applied. Post-retrofit assessment including pushover and time-history analysis of the alternative retrofit solutions revealed the efficiency of the IDS representation as a practical design tool which facilitates direct insight into the interrelation between drift demand and the required dimensions and details of the retrofit scenario.

\section{ACKNOWLEDGMENTS}

In conducting this research the authors benefited from the support and access to the facilities of their respective institutions. The research conducted by the third author was sponsored by the Mid-America Earthquake Center, a US National Science Foundation Engineering Research Center, funded under grant EEC 97-01785. 


\section{REFERENCES}

Aschheim, M. A., and Black, E. F. (2000). "Yield Point Spectra for seismic design and rehabilitation.” EERI Earthquake Spectra, 16(2), 317-336.

CEB Bulletin d' Information No 220 (1994). "Behaviour and analysis of RC structures under alternate actions inducing inelastic response, Vol. 2: Frame members" Report, Lausanne, 380 .

Clough, R. W., and Penzien, J. (1993). Dynamics of Structures, 2nd Edition, McGraw-Hill International Editions, 738.

Deutsches Institut für Normung (DIN). (1972). "Beton un Stahlbetonbau: Bemessung und Ausführung. " DIN 1045, Berlin.

Elnashai, A. S., Papanikolaou, V., and Lee, D.-H. (2002). “ZEUS-NL User Manual.” MidAmerica Earthquake Center Report, Univ. of Illinois at Urbana-Champaign, $<$ http://mae.ce.uiuc.edu/software_and_tools/zeus_nl. html $>$.

Eurocode 8 (2004). "Design of structures for earthquake resistance - Part 1: General rules, seismic actions and rules for buildings." EN1998-1-2004:E, European Committee for Standardization (CEN), Brussels.

Eurocode 8 (2005). "Design of structures for earthquake resistance. Part 3: Assessment and retrofitting of buildings.” EN 1998-3:2005(E), European Committee for Standardization (CEN), Brussels.

Gülkan, P., and Sozen, M. A. (1996). "Procedure for determining seismic vulnerability of building structures.” ACI Struct. J., 96(3), 336-342.

KANEPE, Interventions Code (of Greece). Earthquake Planning and Protection Organization (E.P.P.O.), Final draft, Sep. 2010 (in Greek).

Pardalopoulos, P., and Pantazopoulou, S. J. (2010). "Spatial component analysis of 3-D displacement and storey drift in RC buildings under seismic loads", Proc. in Computational Methods in Earthquake Engineering, (Ed.: M. Papadrakakis et al.), Springer Publ.

Paulay, T., and Priestley, M. J. N. (1992). Seismic design of reinforced concrete and masonry buildings. J. Wiley and Sons Inc., New York, 744.

Pinto, A., Verzeletti, G., Molina, J., Varum, H., Pinho, R., and Coehlo, E. (2002). "Pseudodynamic tests on non-seismic resisting RC frames (bare and selective retrofit frames)." EUR Report 20244EN, Joint Research Institute, Ispra, Italy. 
Thermou, G. E., Pantazopoulou, S. J., and Elnashai, A. S. (2009). "Design and assessment models and spectra for repaired reinforced concrete structures." Mid-America Earthquake Center Report, CD release 09-01.

\section{NOTATION}

The following symbols are used in this paper:

$A_{J}\left(=\rho_{J} A_{f l}\right), A_{m}=\left(\rho_{m} A_{f l}\right), A_{w}=\left(\rho_{m w} A_{f l}\right)=$ cross-sectional area of columns, masonry infills and walls given as ratios of floor area, $A_{f l}$;

$b_{c}, b_{J}=$ width of the initial and the jacketed cross section, respectively;

$c \quad=$ compression zone depth;

$D_{b} \quad=$ bar diameter of longitudinal reinforcement;

$d_{J}, d_{w}=$ depth of the jacketed and wall cross section, respectively;

$E_{c}, E_{s}=$ elastic modulus of concrete and steel;

$\underline{F} \quad=$ flexibility matrix (referring to the translational degrees of freedom);

$f_{b y} \quad=$ bond stress at yield;

$f_{w k} \quad=$ compressive strength of masonry;

$f_{y} \quad=$ steel stress at yield;

$h_{i} \quad=$ storey height;

$h_{c, j} \quad=$ the free column length;

$h_{J}, h_{w}=$ height of the jacketed and wall cross section, respectively;

$I D_{, i}, I D_{1}=$ elastic interstorey drift for the $\mathrm{i}$-th and for $1^{\text {st }}$ storey, respectively;

$I D_{y, \text { target }, i}, I D_{y, \text { target }}=$ target interstorey drift at yield for the i-th and for $1^{\text {st }}$ storey, respectively;

$I_{y}^{J}, I^{w}{ }_{y}=$ moment of inertia at yield for RC jacketed members and RC walls, respectively;

$i_{J}, i_{w}=$ the radius of gyration of the jacketed-column and the wall cross sections;

$K^{*} \quad=$ generalized stiffness;

$K_{i} \quad=$ stiffness of the i-th floor; 
$L_{b} \quad$ = beam length;

$l_{m w} \quad=$ cross-sectional width of masonry walls;

$\underline{m} \quad=$ mass matrix

$M^{*} \quad$ = generalized mass;

$m_{i} \quad=$ mass of the $\mathrm{i}$-th floor;

$n \quad=$ total number of floors;

$q \quad$ = behavior factor;

$S \quad=$ soil parameter;

$T \quad$ period;

$T_{B}, T_{C}=$ period values that define the limits of the constant acceleration branch;

$T_{D} \quad=$ period value defining the constant displacement range in the spectrum

Greek symbols:

$\alpha_{c, b}, \alpha_{c, J}=$ restraint coefficient for RC beams and columns;

$\alpha_{g} \quad=$ design ground acceleration;

$\Delta_{\text {top }} \quad=$ displacement at the top of the building;

$\Delta_{y} \quad=$ yield displacement at the top of the building;

$\Delta_{u} \quad=$ ultimate displacement at the top of the building;

$\theta_{i}\left(=\Delta \Phi_{i} / h_{i}\right)=$ interstorey drift;

$\lambda \quad=$ factor accounting for the flexural stiffness ratios of the horizontal and vertical members at any floor;

$\mu \quad=$ member's ductility demand;

$\mu_{\text {target }}=$ systems' target ductility demand;

$v\left(=N /\left(b_{J} h_{J} f_{c}^{\prime}\right)=\right.$ dimensionless axial load;

$\xi_{J}\left(=c / d_{J}\right), \xi_{w}\left(=c / d_{w}\right)=$ norm. compression zone depth at yielding for column and wall sections; 


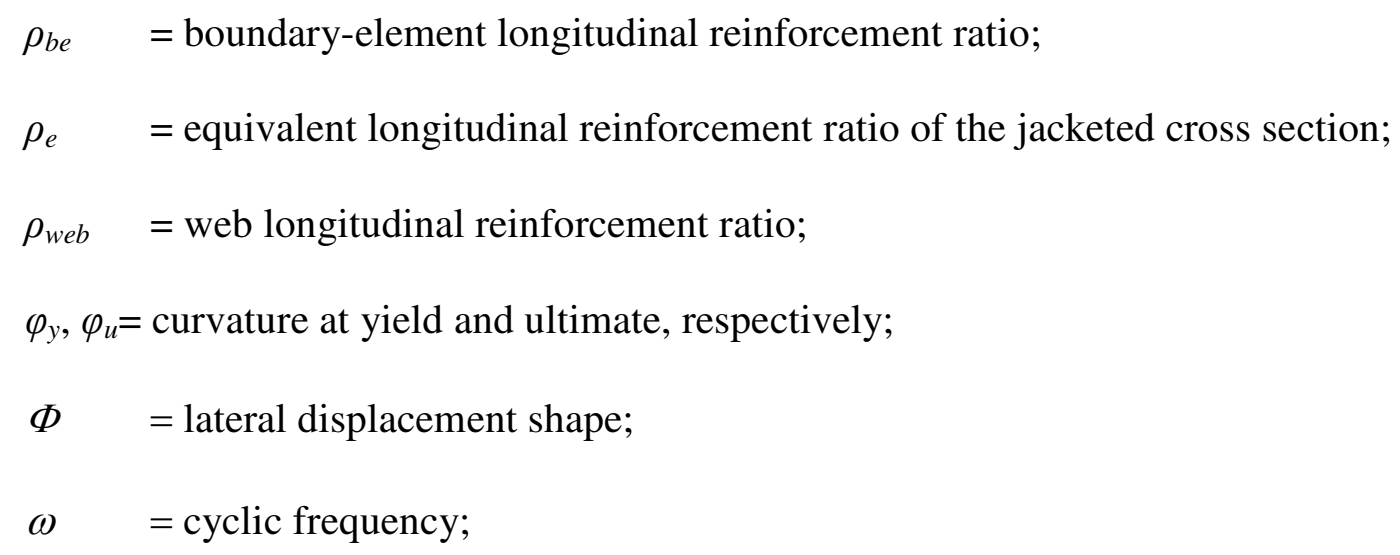
characteristics of the global intervention considered and the materials used (Eqs. (16)). 


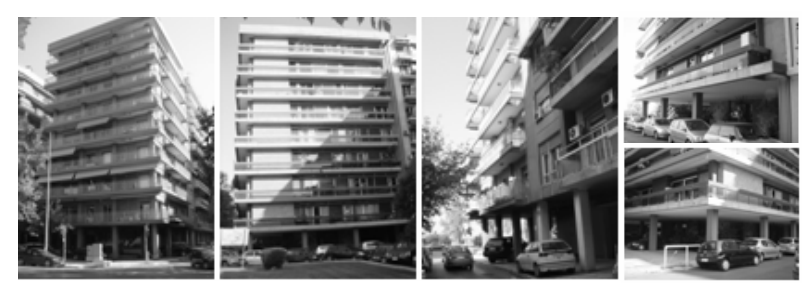

Fig. 1. Open first storey (pilotis) frames - typical residential structures in Southern Europe.

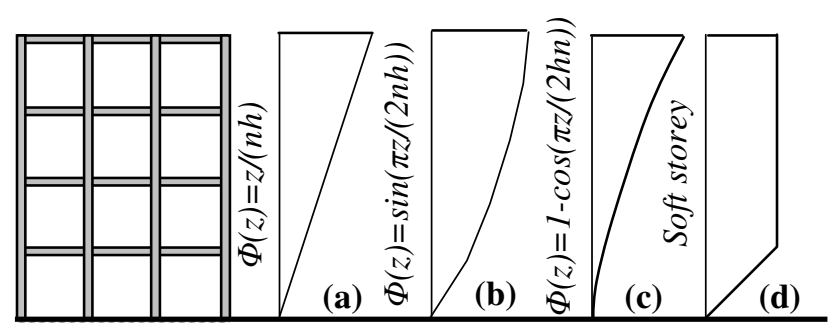

Fig. 2. Lateral displacement profiles (a) triangular; (b); shear-type; (c) flexural; (d) soft storey.
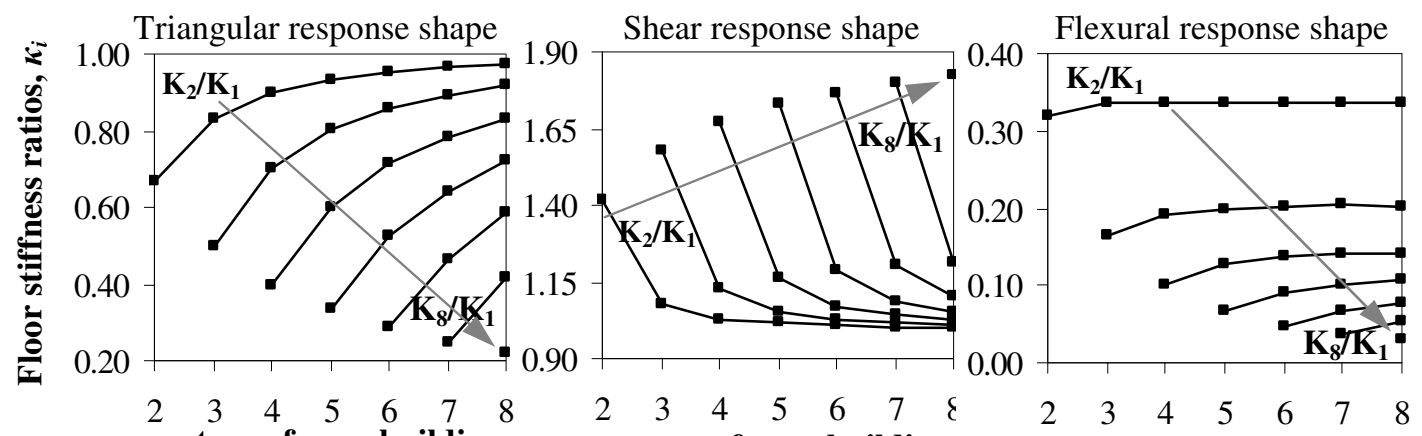

(a) n-storey frame building (b) n-storey frame building (c) n-storey frame building

Fig. 3. Floor stiffness ratios $\kappa_{i}\left(=K_{i}: K_{l}\right)$ for different lateral deflection shape patterns for 2- up to 8storey frame buildings. For example, a 3-storey structure will follow a sinusoidal (shear), a triangular, or a flexural response shape for $\kappa_{2}=K_{2} / K_{1}=1.08, \kappa_{2}=0.85$, and $\kappa_{2}=0.34$ respectively. For intermediate $\kappa_{i}$ values the response shape lies either to the right, or to the left of the triangular profile (i.e., between sinusoidal and triangular, or between triangular and flexural profiles, respectively). 


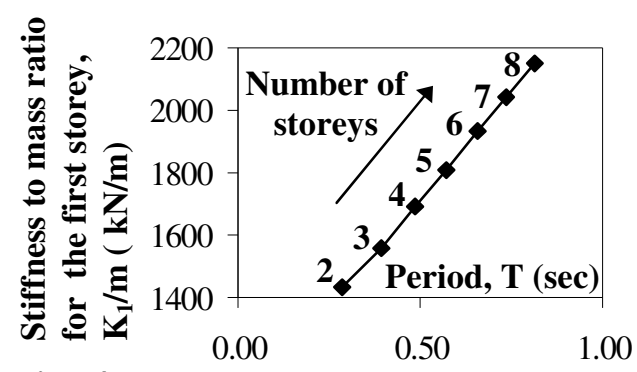

Fig. 4. Stiffness to mass ratio for the first storey, $K_{l} / m$, vs period for up to 8 -storey frames. Required $K_{l}$ values are obtained by multiplying the ordinate with the mass $m$ (in tons).
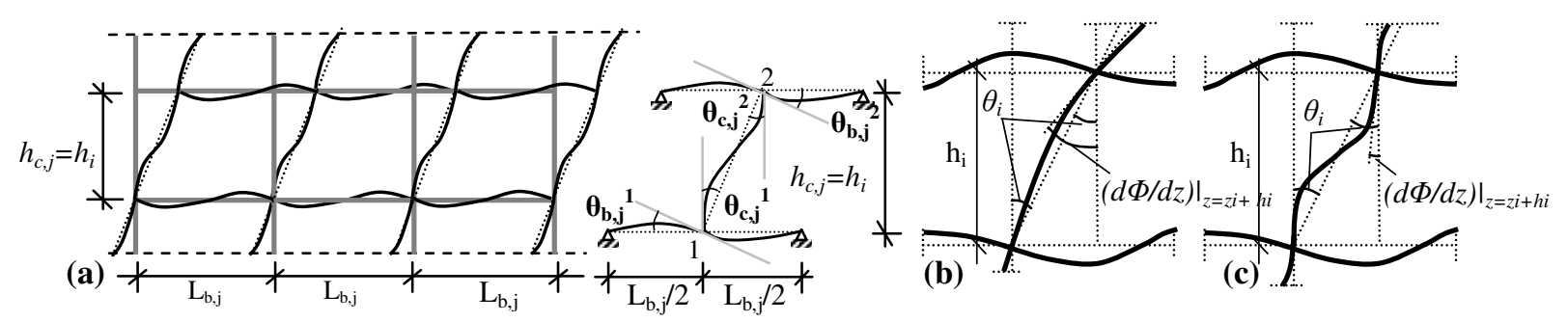

Fig. 5. (a) Frame structure under lateral sway; (b) Flexural-type; (c) Shear-type response floor rotations.

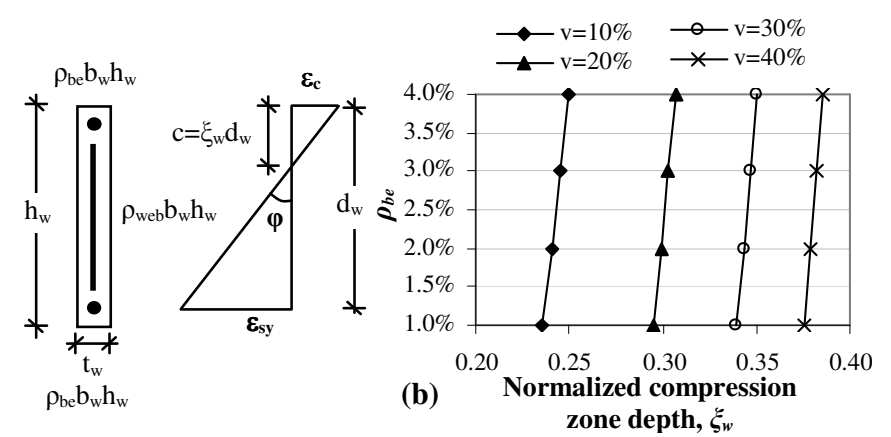

Fig. 6. (a) Wall cross-sectional equilibrium at first yield, definition of terms; (b) Variation of the $\xi_{w}, \rho_{b e}$, and $v$. 
(a)

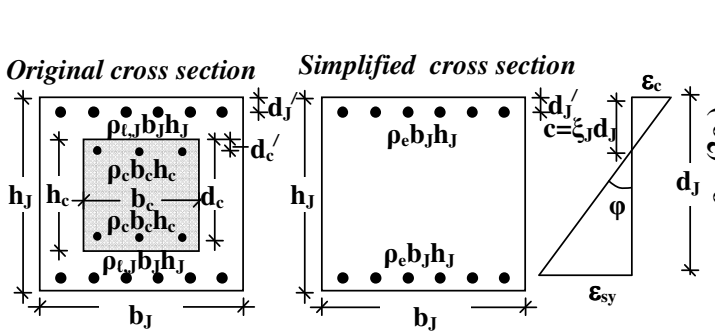

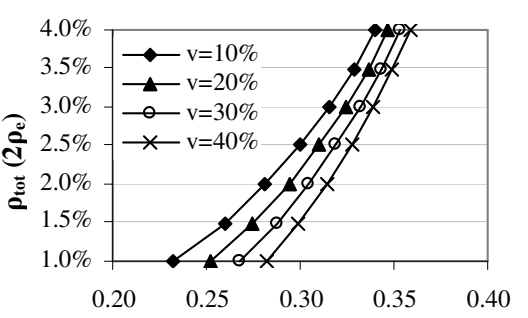

(b) Normalized compression zone depth, $\xi_{J}$

Fig. 7. (a) Simple model for RC jacketed cross section; (b) Relationship between $\xi_{J}$, $\rho_{\text {tot }}$ and $v$.

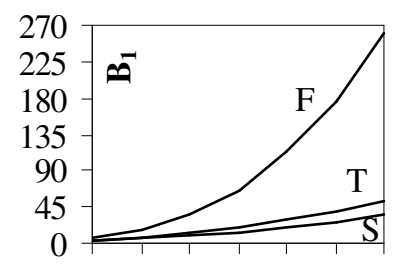

$\begin{array}{lllllll}2 & 3 & 4 & 5 & 6 & 7 & 8\end{array}$

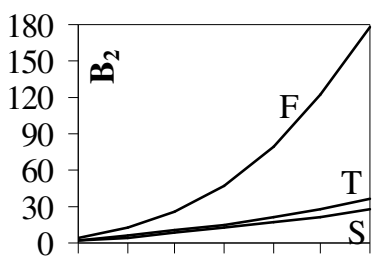

$\begin{array}{lllllll}2 & 3 & 4 & 5 & 6 & 7 & 8\end{array}$

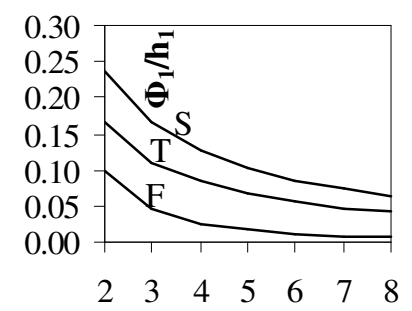

n-storey frame building

$F$ : flexural response shape, $T$ : triangular response shape, $S$ : shear response shapes

Fig. 8. Parameters $B_{1}, B_{2}, \Phi_{1} / h_{1}$ for 2- up to 8 -storey buildings $\left(\Phi_{1} / h_{1}\right.$ has been estimated for $\left.h_{l}=3 \mathrm{~m}\right)$.

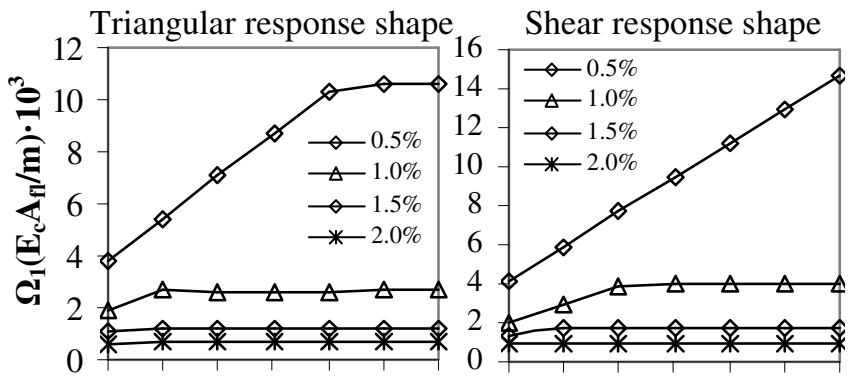

Flexural response shape

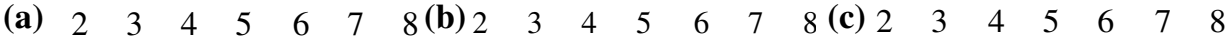
n-storey frame building $n$-storey frame building n-storey frame building

Fig. 9 Design charts that relate directly the elastic drift demand of the first storey with the stiffness coefficient of the first storey, $\Omega_{l}$ for the (a) triangular; (b) shear; (c) flexural response. 

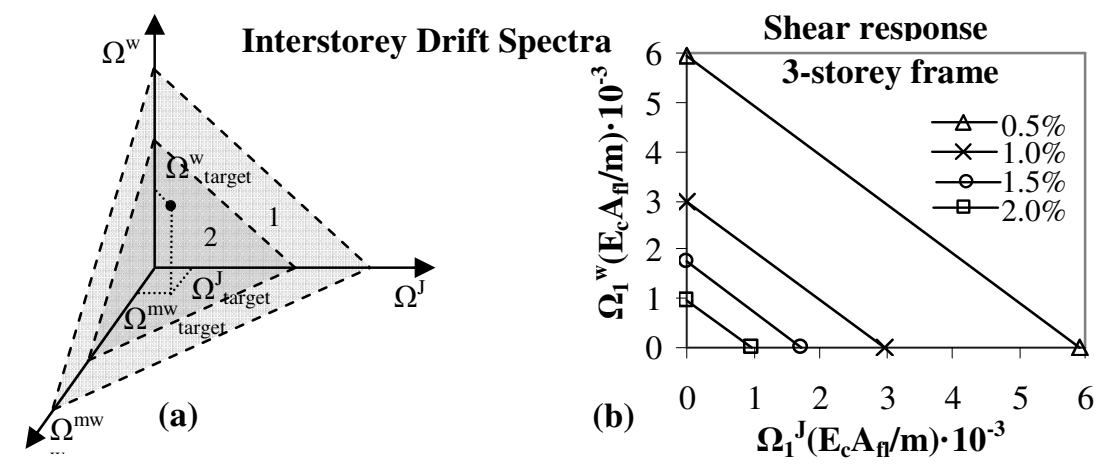

Fig. 10. Interstorey Drift Spectra (IDS) (a) 3D plot where all the stiffness parameters $\Omega^{J}, \Omega^{w}, \Omega^{m w}$ are related; (b) 2D plot where RC jacketing is combined with RC walls.

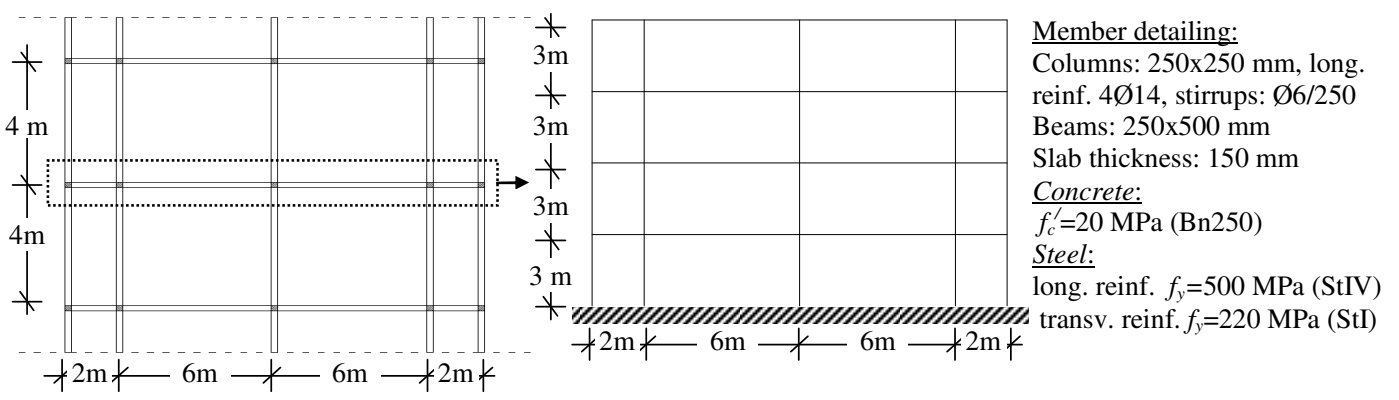

Fig. 11. (a) Plan; (b) Elevation of the existing frame structure; member detailing and material properties.

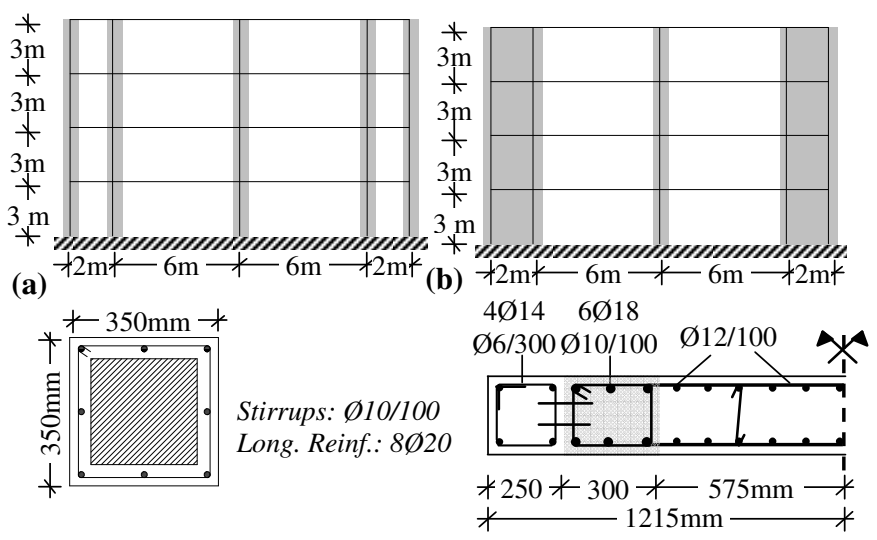

Fig. 12. (a) RS1: RC column jacketing; (b) RS2: RC infill walls and selective RC column jacketing. 

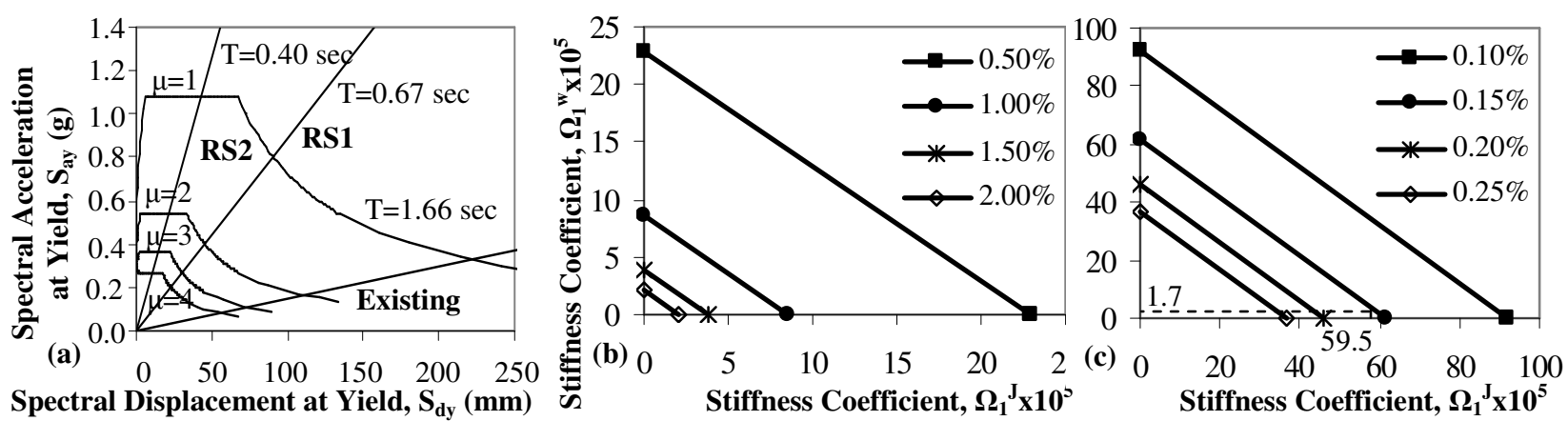

Fig. 13. (a) Yield Point Spectra for EC8 Type I; Interstorey Drift Spectra for retrofit by (b) RC column jacketing; (c) infill walls and selective RC column jacketing.
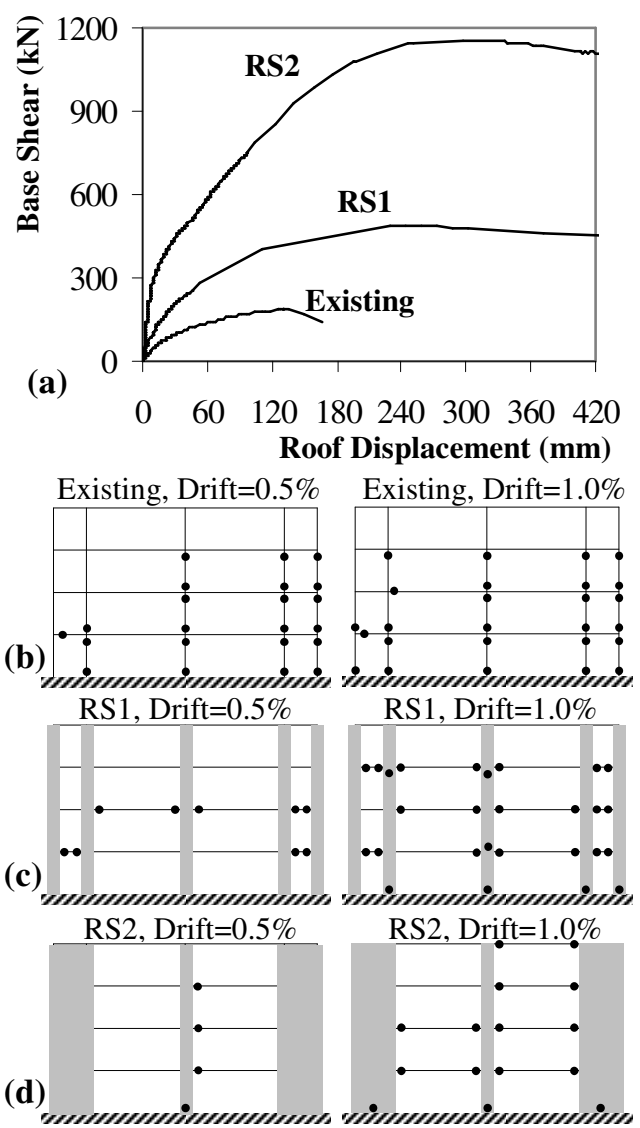

Fig. 14. (a) Comparison of the responses of retrofitted structures and the original model; Distribution of plastic hinges at $0.5 \%$ and $1.0 \%$ drift for (b) existing frame; (c) RS1; (d) RS2. 

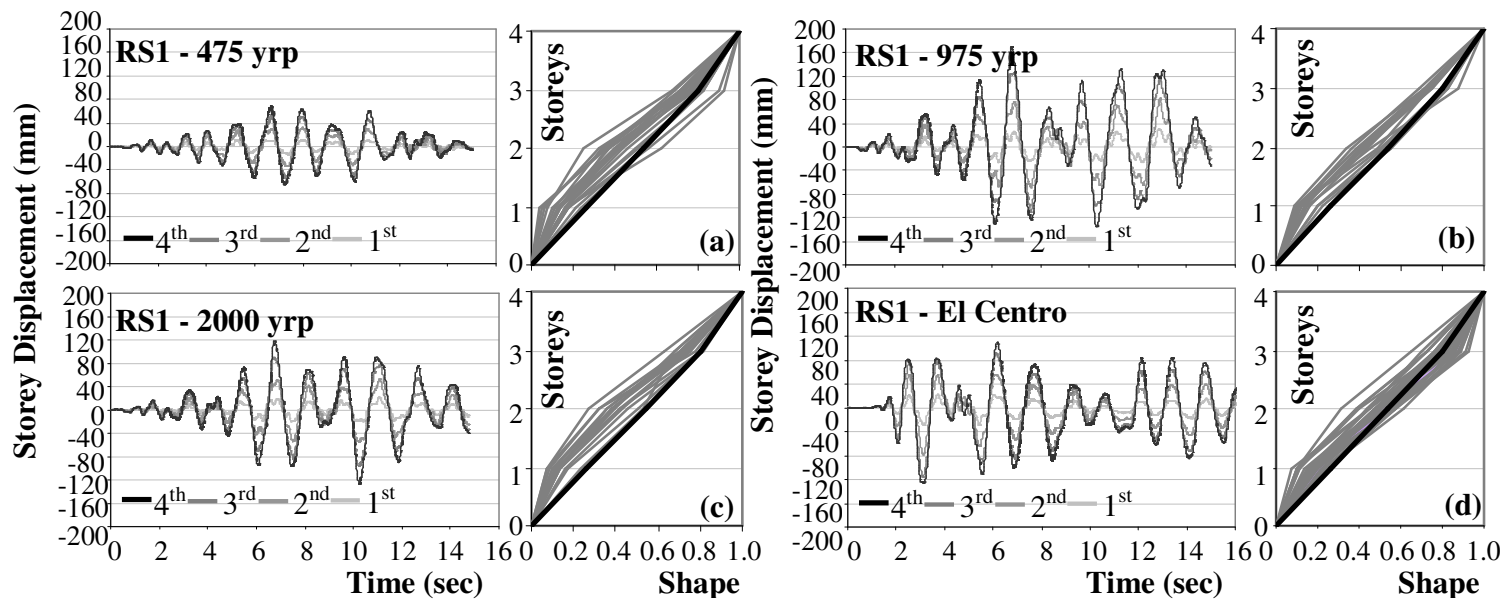

Fig. 15. Storey displacement time histories and comparison of the post-design fundamental response shape (black solid line) with the response profiles (group of gray colored curves) corresponding to points of peak roof displacement response obtained under (a) 475yrp; (b) $975 \mathrm{yrp}$; (c) $2000 \mathrm{yrp}$; (d) El Centro ground motions for the RS1 retrofit solution.
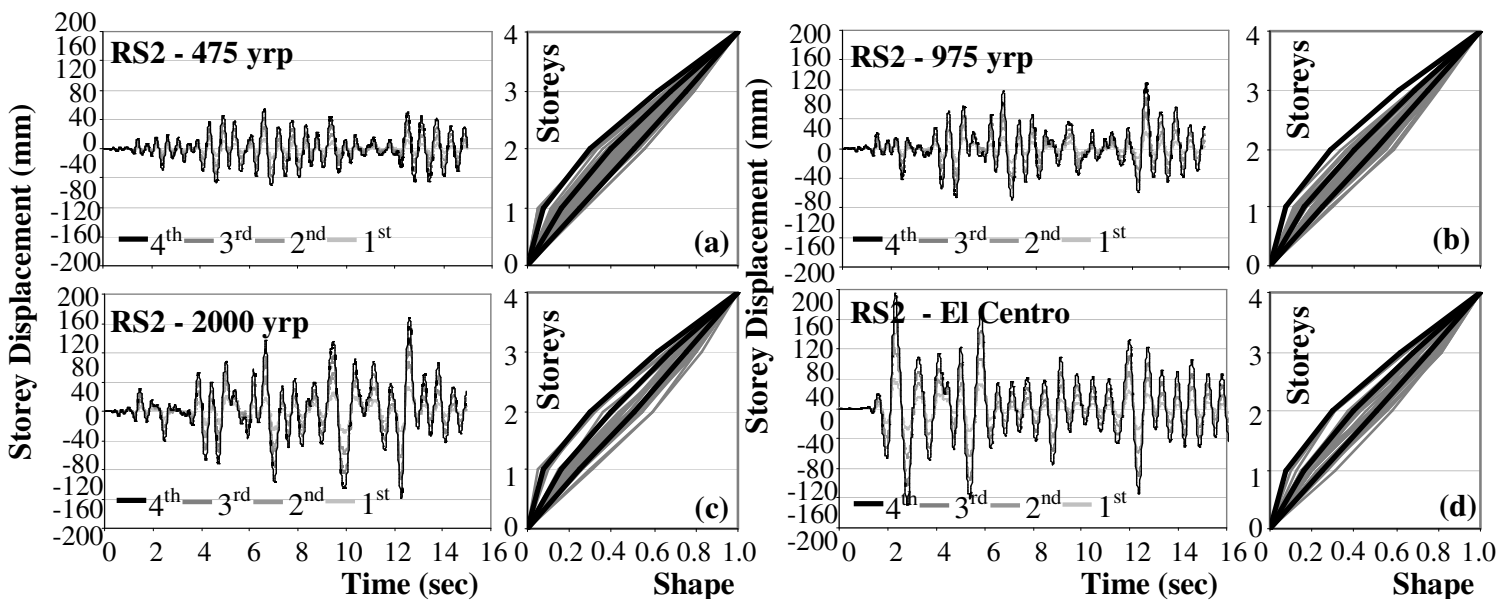

Fig. 16. Storey displacement time histories and comparison of the post-design fundamental response shape (black solid line) with the response profiles (group of gray colored curves) corresponding to points of peak roof displacement response obtained under (a) 475yrp; (b) $975 \mathrm{yrp}$; (c) $2000 \mathrm{yrp}$; (d) El Centro ground motions for the for the RS2 retrofit solution. 
(a) 475 yrp

(b) 975 yrp

(c) $2000 \mathrm{yrp}$

(d) El Centro
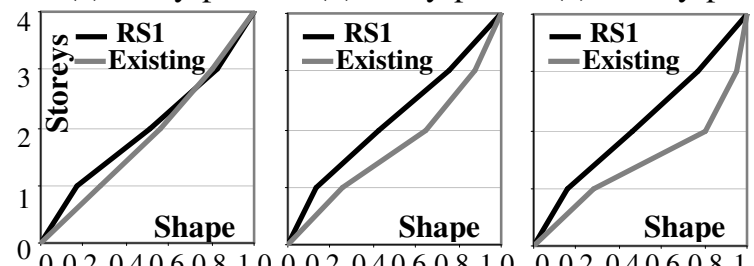

二 Existing

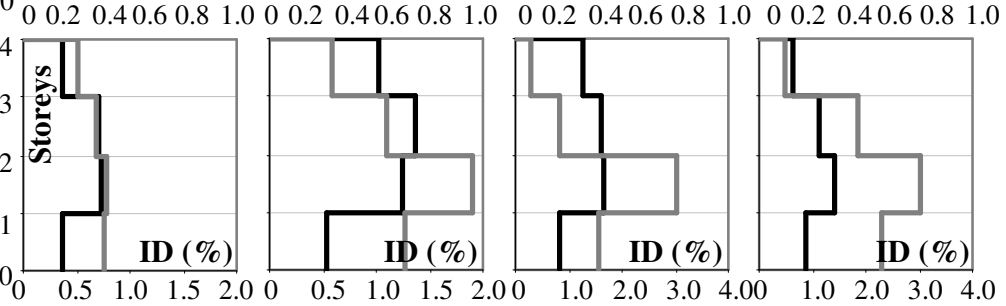

Fig. 17. Comparison of the displacement and interstorey drift profiles at maximum top displacement for the existing and the retrofitted by the RS1 retrofit solution frames for (a) 475yrp; (b) $975 \mathrm{yrp}$; (c) $2000 \mathrm{yrp}$; (d) El Centro ground motions.

(a) 475 yrp

(b) 975 yrp

(c) 2000 yrp

(d) El Centro
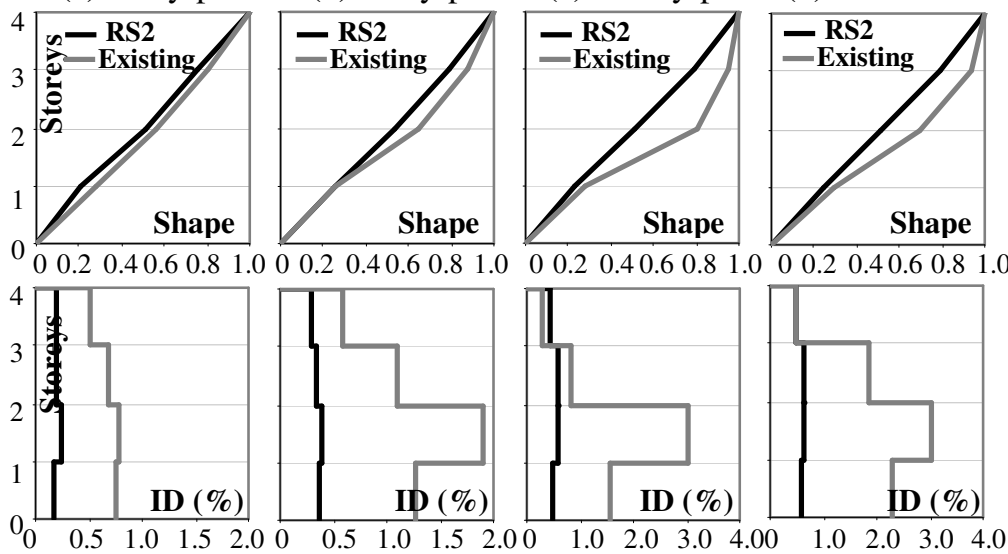

Fig. 18. Comparison of the displacement and interstorey drift profiles at maximum top displacement for the existing and the retrofitted by the RS2 retrofit solution frames for (a) 475yrp; (b) $975 \mathrm{yrp}$; (c) $2000 \mathrm{yrp}$; (d) El Centro ground motions. 

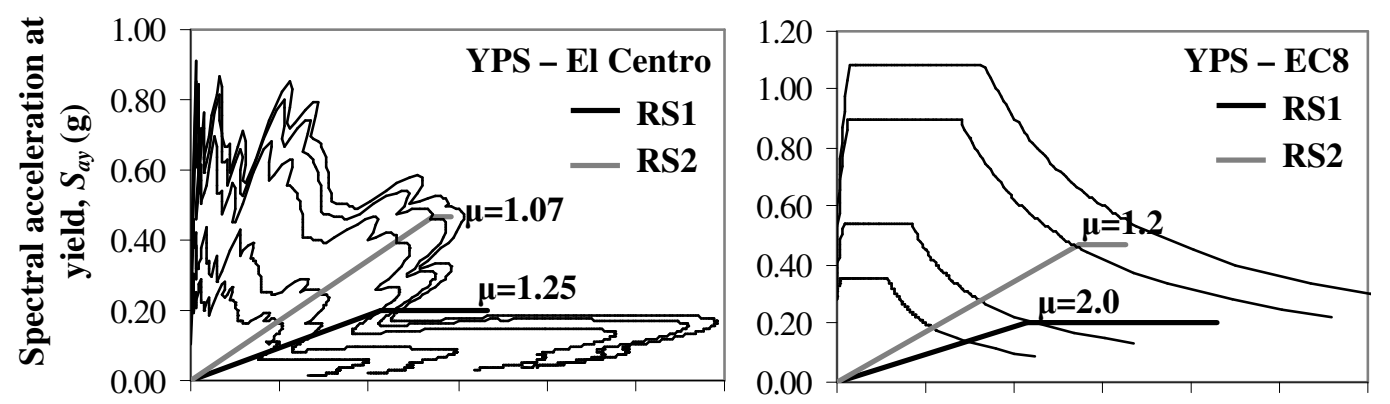

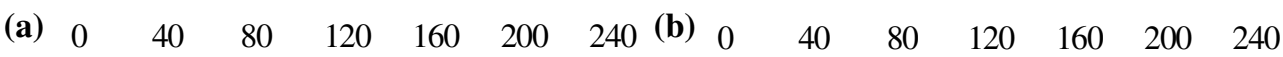
Spectral displacement at yield, $S_{d y}(\mathrm{~mm})$

Fig. 19. Assessment of retrofit solutions using the YPS of the (a) El Centro (1940) ground motion; (b) EC8 design spectra. 
Table 1. Reference stiffness ratios for the various response shapes.

\begin{tabular}{|c|c|c|}
\hline Shape & & Stiffness ratios, $\kappa_{i}=K_{i} / K_{1}$ where $i=2, \ldots, \mathrm{n}$ \\
\hline Triangular & $\Phi(i)=i /(n)$ & $\sum_{i}^{n} i / \sum_{1}^{n} i$ \\
\hline Shear & $\Phi(i)=\sin \left(\frac{\pi i}{2 n}\right)$ & $\frac{\sin (\pi /(2 n)) \sum_{i}^{n} \sin (\pi i /(2 n))}{[\sin (\pi i /(2 n))-\sin (\pi(i-1) /(2 n))] \sum_{1}^{n} \sin (\pi i /(2 n))}$ \\
\hline Flexural & $\Phi(i)=1-\cos \left(\frac{\pi i}{2 n}\right)$ & $\frac{[1-\cos (\pi /(2 n))] \sum_{i}^{n}[1-\cos (\pi i /(2 n))]}{[\cos (\pi(i-1) /(2 n))-\cos (\pi i /(2 n))] \sum_{1}^{n}[1-\cos (\pi i /(2 n))]}$ \\
\hline
\end{tabular}

Table 2. Jacket total equivalent longitudinal reinforcement for the RS1 retrofit solution.

\begin{tabular}{|c|c|c|c|c|}
\hline $\begin{array}{c}\text { Retrofit solution: } \\
\text { RS1 }\end{array}$ & $\begin{array}{c}1^{\text {st }} \\
\text { storey }\end{array}$ & $\begin{array}{c}2^{\text {nd }} \\
\text { storey }\end{array}$ & $\begin{array}{c}3^{\text {rd }} \\
\text { storey }\end{array}$ & $\begin{array}{c}4^{\text {th }} \\
\text { storey }\end{array}$ \\
\hline $\begin{array}{c}\text { Member target } \\
\text { stiffness }(\mathrm{kN} / \mathrm{m})\end{array}$ & 10542 & 9488 & 7379 & 4217 \\
\hline$\rho_{\text {tot }}\left(2 \rho_{e}\right)$ & $2.3 \%$ & $2.1 \%$ & $1.6 \%$ & $1.3 \%$ \\
\hline$\rho_{J}\left(A_{J} /\left(b_{J} h_{J}\right)\right.$ & $\begin{array}{c}2.1 \% \\
(8 Ø 20)\end{array}$ & $\begin{array}{c}1.8 \% \\
(8 Ø 18)\end{array}$ & $\begin{array}{c}1.3 \% \\
(8 \emptyset 16)\end{array}$ & $\begin{array}{c}1.0 \% \\
(8 \emptyset 14)\end{array}$ \\
\hline
\end{tabular}

Table 3. Drift values at maximum top displacement for the existing frame and the two retrofit solutions subjected to dynamic time history analyses.

\begin{tabular}{|c|c|c|c|c|}
\hline Existing & $475 \mathrm{yrp}$ & $975 \mathrm{yrp}$ & $2000 \mathrm{yrp}$ & El Centro \\
\hline$I D(\%)$ & 0.81 & 1.27 & 1.44 & $1.93^{*}$ \\
\hline $\mathrm{RS} 1$ & $475 \mathrm{yrp}$ & $975 \mathrm{yrp}$ & $2000 \mathrm{yrp}$ & El Centro \\
\hline$I D(\%)$ & 0.58 & 1.06 & 1.41 & 1.05 \\
\hline $\mathrm{RS} 2$ & $475 \mathrm{yrp}$ & $975 \mathrm{yrp}$ & $2000 \mathrm{yrp}$ & El Centro \\
\hline$I D(\%)$ & 0.21 & 0.37 & 0.55 & 0.62 \\
\hline
\end{tabular}

at $\mathrm{t}=5.8 \mathrm{sec}-$ from that point onwards the solution does not diverge 


\section{Appendix:}

Table A1

\begin{tabular}{|c|c|c|c|c|c|c|c|}
\hline \multicolumn{7}{|c|}{$\Theta_{w, j}{ }^{A} \cdot h_{i}{ }^{2}$ values for the flexural response shape $\left(\Phi_{i}=1-\cos (\pi i /(2 n))\right)$} \\
\hline $\mathrm{n}$ & 2 & 3 & 4 & 5 & 6 & 7 & 8 \\
\hline 1st floor & 0.308425 & 0.068539 & 0.022584 & 0.009425 & 0.004591 & 0.002350 & 0.001467 \\
\hline 2nd floor & 0.052917 & 0.036730 & 0.016231 & 0.007670 & 0.003987 & 0.002250 & 0.001357 \\
\hline 3rd floor & - & 0.004921 & 0.007247 & 0.004831 & 0.002940 & 0.001810 & 0.001152 \\
\hline 4th floor & - & - & 0.000894 & 0.001991 & 0.001731 & 0.001263 & 0.000885 \\
\hline 5th floor & - & - & - & 0.000236 & 0.000684 & 0.000715 & 0.000596 \\
\hline 6th floor & - & - & - & - & 0.000080 & 0.000275 & 0.000329 \\
\hline 7th floor & - & - & - & - & - & 0.000032 & 0.000125 \\
\hline 8th floor & - & - & - & - & - & - & 0.000014 \\
\hline
\end{tabular}

Table A2

\begin{tabular}{|c|c|c|c|c|c|c|c|}
\hline \multicolumn{7}{|c|}{$\Theta_{w, j}{ }^{B} \cdot h_{i}{ }^{2}$ values for the flexural response shape $\left(\Phi_{i}=1-\cos (\pi i /(2 n))\right)$} \\
\hline $\mathrm{n}$ & 2 & 3 & 4 & 5 & 6 & 7 & 8 \\
\hline 1st floor & 0.077801 & 0.017163 & 0.005649 & 0.002357 & 0.001148 & 0.000590 & 0.000367 \\
\hline 2nd floor & 0.017276 & 0.009394 & 0.004081 & 0.001922 & 0.000998 & 0.000563 & 0.000339 \\
\hline 3rd floor & - & 0.001625 & 0.001864 & 0.001218 & 0.000737 & 0.000453 & 0.000288 \\
\hline 4th floor & - & - & 0.000296 & 0.000514 & 0.000437 & 0.000317 & 0.000222 \\
\hline 5th floor & - & - & - & 0.000079 & 0.000177 & 0.000181 & 0.000150 \\
\hline 6th floor & - & - & - & - & 0.000026 & 0.000071 & 0.000083 \\
\hline 7th floor & - & - & - & - & - & 0.000011 & 0.000032 \\
\hline 8th floor & - & - & - & - & - & - & 0.000005 \\
\hline
\end{tabular}

